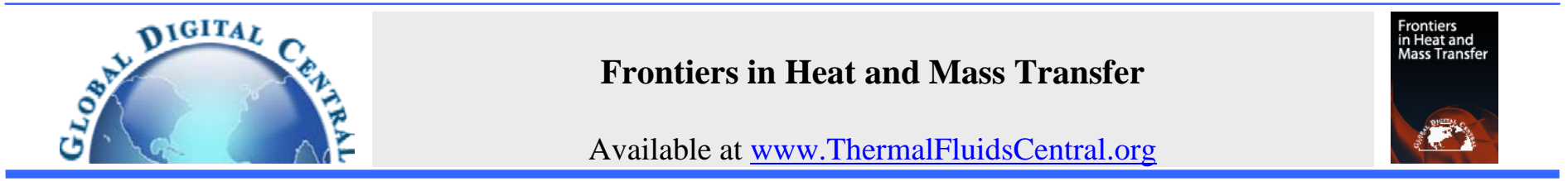

\title{
A REVIEW OF RECENT PROGRESS ON NANO/MICRO SCALE NUCLEATE BOILING FUNDAMENTALS
}

\author{
J.N. Chung ${ }^{\mathrm{a}, \dagger}$, Tailian Chen ${ }^{\mathrm{b}}$, Shalabh C. Maroo ${ }^{\mathrm{c}}$ \\ ${ }^{a}$ Department of Mechanical and Aerospace Engineering, University of Florida, Gainesville, FL, 32611,USA \\ ${ }^{\mathrm{b}}$ Department of Mechanical Engineering, Gonzaga University, Spokane, WA, 99258, USA \\ ${ }^{\text {c }}$ Department of Mechanical Engineering, Massachusetts Institute of Technology, Cambridge, MA, 02139, USA
}

\begin{abstract}
Recent research progress in the area of nano/micro scale nucleate boiling is reviewed and an up-to-date summary is provided with a focus on the advances of fundamental boiling physics. This review examines nano/micro scale pool boiling experimental and theoretical/numerical work reported in the open literature. On the experimental side, the topics covered are moving contact line, critical heat flux, boiling curve, nucleation, single bubble boiling cycle, bubble coalescence boiling cycle, heater size effect, nanofluid, and nanoscale-structured heater surface. For the theoretical/numerical work, continuum mechanics modeling of the micro-region and molecular dynamics modeling of the nano-region are included.
\end{abstract}

Keywords: Nucleate boiling, nano/micro scale, critical heat flux, moving contact line, bubble coalescence

\section{INTRODUCTION}

Nucleate boiling has been recognized as one of the most efficient heat transfer mechanisms. In many engineering applications that require super-high heat transfer rates, nucleate boiling heat transfer is the mode of choice. Boiling heat transfer holds the potential advantage of facilitating the transfer of a large amount of energy over a relatively narrow temperature range with a small weight to power ratio.

For a secure energy future the energy conversion efficiency must be advanced. All types of advanced power devices and high-tech electronic systems ranging from heavy-vehicle engines, computer chips and advanced nuclear reactors depend on efficient thermal energy transport mechanisms to acquire heat input and to reject waste heat for the purpose of achieving higher power density and higher system efficiency. Higher cooling rates can increase energy conversion system efficiency, enable higher power density and also elevate system functionality (for example, higher throughput for rocket engines and higher power density for nuclear reactors). Furthermore, as advanced micro-mechanical, microelectronic, and photonic device technologies have led to ever smaller structures, heat dissipation has become an increasingly important problem that will limit the performance. In fact, due to the lack of a breakthrough in advanced cooling technology, the computer processor speed has reached its limit with conventional cooling and the future of tera-hertz computers is now in doubt.

Correspondingly, higher and higher system operating temperatures and power densities are becoming the goals of future energy systems. Accordingly, researchers are turning to untraditional and modern convective thermal energy transport mechanisms for solutions as the conventional convective heat transfer technologies have reached their limits. The fundamental research on nucleate boiling would unveil the controlling boiling mechanisms such that the next breakthrough in cooling technology, for example using nano fluids and nano surface textures, can be realized. So, fundamental boiling research will directly benefit the high heat flux power and cooling industry, especially for the cooling of electronics and nuclear reactors, by providing new dimensions in modeling and simulation capabilities for engineering design and development.

Apart from the engineering importance, there are science issues. Even though the critical heat flux point is crucial to the safe operation of a boiling system, currently, a complete understanding of the physics on critical heat flux remains elusive. As a matter of fact controversies over the basic transport mechanisms of bubble coalescence and its effects on the roles of microlayer and macrolayer, liquid re-supply, and heater surface property continue to puzzle the research community. Boiling is also an extremely complex and illusive process. Although a very large number of investigators have worked on boiling heat transfer during the last half century, unfortunately for a variety of reasons, far fewer efforts have focused on the fundamental physics of boiling process. Most of the reported work have been tailored to meeting the needs of engineering applications and as a result have led to correlations involving several adjustable parameters and limited range of applications. The correlations provide quick input to design, performance and safety issues, hence they are attractive on a short term basis. However, the usefulness of the correlations diminishes very rapidly as parameters of interest start to lie outside the range for which the correlations were developed. With the advancement of nano/micro scale technologies and the availability of more powerful computers, researchers have been making both experimental findings and computational predictions that shed more lights towards unlocking the secrets of nucleate boiling and CHF. This paper is intended to provide a

\footnotetext{
† Corresponding author, Email : jnchung@ufl.edu
} 
review and summary on the recent progress in the fundamental understanding of nano/micro scale nucleate boiling phenomena.

\section{BACKGROUND AND PHYSICS OF NUCLEATE BOILING}

\subsection{Basic Concepts}

It has been widely accepted in the literature that the contact line at the base of the bubble in nucleate boiling can be divided into nano-, microand macro-regions. The micro region is the ultrathin liquid film between the solid surface and the evolving liquid-vapor interface. The macro region is the region occupied by vapor and liquid, except the microlayer. The micro-region can be subdivided into two additional regions. Thus the three regions, as shown in Fig. 1, are:

a) Non-evaporating thin-film region - liquid is adsorbed on the heater surface and forms a non-evaporating layer with molecular forces having controlling influence

b) Evaporating thin-film region - maximum evaporation and heat transfer occurs in this region and the liquid is fed from the bulk liquid through the intrinsic meniscus region

c) Intrinsic meniscus region - fluid mechanics in this region is governed by the conventional equation of capillarity

There is a region between the non-evaporating thin film region and the evaporation thin film region over which the film varies in thickness and curvature to accommodate the transition between the two regions. This is called the interline region and is the thinnest portion of the meniscus over which vaporization can occur. Since it is the thinnest, it is also the location where the evaporation rate is the highest.

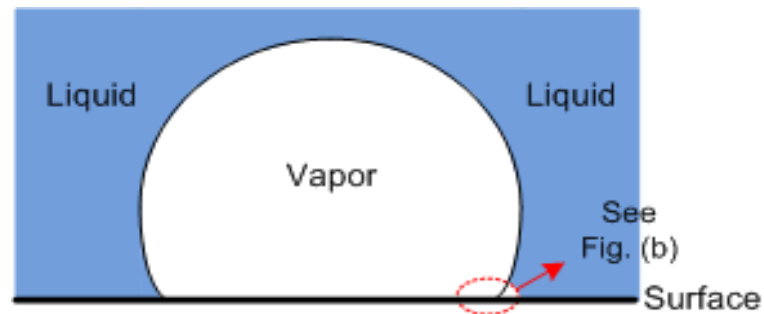

(a)

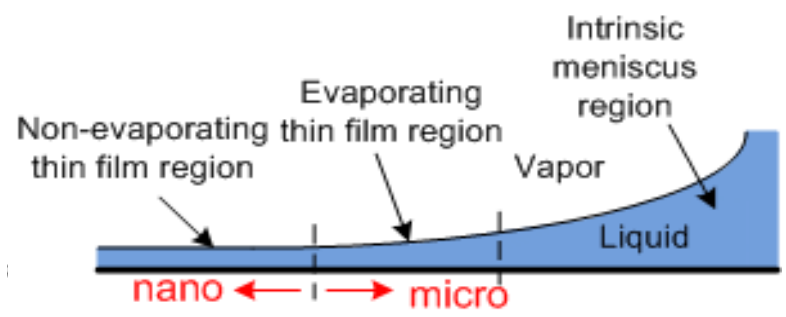

(b)

Fig. 1 Schematic of bubble growth, (a) overall picture at macro-scale (shaded region depicts the area covered by non-evaporating thin film), and (b) zoomed in nano- and micro-scale regions at the three-phase contact line.

Boiling has been studied extensively during the last few decades which include experimental work, and theoretical models to predict the exact nature of boiling in various conditions. Since the boiling process is very complex, its complete understanding still poses significant challenges and researchers have not converged on a definite precise model. The past efforts can be categorized into three broad groups (Dhir 2006):

1) Empirical correlations - experimental data was obtained for boiling heat transfer as a function of several independent variable like heater size, heating method, heater thickness, system pressure, liquid temperature, flow conditions, etc. This data was correlated by many researchers. Although the correlations have been helpful in application to practical situations, they serve their useful purpose only when applied in the range of the database used in developing the correlations.

2) Mechanism-based correlations - This involved studying some of the individual subprocesses to develop mechanistic models for predicting heat fluxes as a function of wall superheat or other independent variables. An expression for partial nucleate boiling heat flux was written based on the contributions of three mechanisms by: transient conduction into the liquid during the waiting period over the region influenced by vapor bubbles, natural convection over the remaining regions of the heater and evaporative heat transfer from the microlayer underneath the bubble. The expression required the knowledge of three key parameters: number density of active sites, bubble diameter at departure and bubble release frequency. A number of attempts have been made to develop correlations or models for these parameters, but with limited success.

3) Numerical simulation - In order to have a credible predictive model of nucleate boiling, one must include all subprocesses which occur and not guess how one parameter influences the overall process. Thus, a complete numerical simulation of the process is asked for - a tool which has been developed only recently. The region of interest is divided into micro- and macro- regions as mentioned before. Lubrication theory has been widely used to solve for the radial variation of microlayer thickness, while complete conservation of mass, momentum and energy are solved for both phases in the macroregion.

\subsection{Three-Phase Moving Contact Line}

The moving contact line (MCL) is a three-phase phenomenon where immiscible vapor-liquid interface meets the solid surface. The dynamics and thermal transport along the contact line at the leading edge of the liquid film is of particular importance as it drives the entire boiling process. The physical understanding of these phenomena is crucial not just for boiling as they are present almost everywhere in nature and play a vital role in countless industrial and engineering processes such as thin film lubrication, coating of solids, tertiary oil recovery, soldering, spray droplet cooling, and evaporation and condensation in the form of a meniscus (heterogeneous boiling and condensation).

During nucleate boiling from a heated surface, vapor bubbles are nucleated and they start to grow owing to an infusion of vapor mass generated mainly from the MCL region. The MCL moves outward during bubble growth period while it retracts back during the bubble departure stage. At higher heat fluxes, bubble-bubble interaction and coalescence are the responsible mechanisms for achieving high heat transfer rates in heterogeneous nucleate boiling where MCL also plays an important role. Bubble-bubble coalescence creates strong disturbances to the fluid mechanics and heat transfer of the micro-layer and the MCL beneath the bubbles. Because of the complicated nature, the detailed physics and the effects of MCL on the single bubble dynamics and bubble-bubble interaction process have not been completely understood.

The no-slip boundary condition between a fluid flow and a solid surface is generally regarded as a cornerstone in the continuum hydrodynamics, owing to its proven applicability in diverse fluid flows. However decades ago, it was discovered that in immiscible gas-liquid two-phase flows over a solid surface, the moving contact line (MCL), defined as the intersection between the moving gas-liquid interface and the solid surface, is incompatible with the no-slip boundary condition (Moffatt 1964, Huh and Scriven 1971, Dussan and Davis 1974, Dussan 1976 and 1979). These reports showed that there is velocity discontinuity at the MCL which is now well-recognized as the contactline singularity (Shikhmurzaev 2006 and Blake 2006). In the past two 
decades, it has been shown through molecular dynamic (MD) simulations that a near-complete slip indeed takes place at the MCL (Koplik et al. 1988, Thompson and Robbins 1989, and Thompson et al. 1993). This finding presented a challenge for the fluid mechanics community, due to a lack of viable solutions apart from ad hoc fixes that include analytical models (Phan et al. 2006, Qian et al. 2006, and Fuentes and Cerro 2007) and numerical models (Ding and Spelt 2007a,b). In the absence of a viable boundary condition which can reproduce the MD results, an accurate continuum description of the MCL flows at the micro- or nano-scale remains an elusive goal which may never be solved explicitly by continuum fluid mechanics.

\subsection{Critical Heat Flux}

The critical heat flux (CHF) on earth, which is the upper heat transfer limit in the nucleate boiling regime represents a state of momentum and mass balance. Because the buoyancy force strength is relatively constant on earth, for heat fluxes lower than the CHF, this force is more than that required for a complete removal of vapor bubbles formed on the heater surface. At the CHF, the buoyancy force is exactly equal to the force required for a total removal of the vapor bubbles. For heat fluxes greater than the CHF, the buoyancy force is unable to remove all the bubbles, thus resulting in the accumulation and merging of bubbles on the heater surface, which simultaneously leads to a total blanketing of the heater surface by a layer of superheated vapor. It is believed that bubble departure and vapor removal from the heater surface is dominated by vapor generation and bubble coalescence, both of which are hinged on the moving contact line dynamics, as a result, the MCL is closely related to the CHF. It is also the objective of many research efforts to find the relationship between the MCL dynamics of bubbles and the critical heat flux.

The boiling curve was first identified by Nukiyama (1934) more than sixty years ago. Since then the critical heat flux (CHF) has been the focus of boiling heat transfer research. A plethora of empirical correlations for the CHF are now available in the literature, although each is applicable to somewhat narrow ranges of experimental conditions and fluids. Recently a series of review articles (Lienhard 1988a,b, Dhir, 1990, Katto, 1994, Sadasivan et al., 1995, Kandlikar et al., 1999 and Kandlikar 2006) have been devoted to the discussion of progress made in the CHF research. There have been three mechanistic models suggested in the past : 1 . vapor escape path instability model (Zuber, 1959, Lienhard and Dhir, 1973), 2. macrolayer dryout model (Haramura and Katto, 1983) and 3. vapor stem merging model (Dhir and Liaw, 1989). The consensus is that a satisfactory overall mechanistic description for the CHF in terrestrial gravity still remains elusive. The following are some perspectives on issues in CHF modeling elucidated in a recent review by Sadasivan et al. (1995).

- $\quad$ CHF is the limiting point of nucleate boiling and must be viewed as linked to high-heat-flux end of nucleate boiling region and not an independent pure hydrodynamic phenomenon. The experiments dealing with CHF will only be meaningful if measurements of the high heat-flux nucleate boiling region leading up to CHF are made together with the CHF measurement. This would help resolve the issue of the role of dry area formation and the second transition region on CHF. Simultaneous surface temperature measurements are necessary.

- An improved mechanistic explanation of CHF also requires that experimental efforts be directed towards making high resolution measurements of the heater surface temperature. Experiments designed to make transient local point measurements of surface temperature (temperature map) and near surface vapor content will help in developing a clearer picture of the characteristics of the macrolayer and elucidating the role of liquid supply to the heater surface.

- Identifying the heater surface physical characteristics such as active nucleation site distribution, static versus dynamic contact angles, and advancing versus receding angles. These would help understand the heater surface rewetting behavior.

\section{EXPERIMENTAL INVESTIGATIONS}

\subsection{Heat Transfer Mechanisms during Nucleate Boiling}

The boiling curve first introduced by Nukiyama (1934) has been used to describe different regimes during saturated pool boiling. His work also inspired subsequent boiling heat transfer research to understand physical mechanisms responsible for the high heat transfer effectiveness during the boiling process, which established fundamental understanding of physical mechanisms during nucleate boiling process. Early work can be categorized into bubble-agitated enhancement and microlayer evaporation enhancement. The former is represented by many concepts (Rosenhow, 1952; Forster and Zuber, 1955; Forster and Grief, 1959; Tien, 1962; Zuber, 1963; Han and Griffith, 1965; Mikic et al., 1969) that proposed models assuming that bubble agitation and microconvection were the primary heat transfer mechanisms. Typical of these was the work by Mikic et al. (1969) who proposed the transient conduction model, which assumed a departing bubble scavenged away the superheated layer surrounding the bubble in an area twice the bubble departure diameter and allowed the colder bulk liquid to contact the surface. This model predicted a very large heat transfer rate immediately after the bubble departed from the surface over an area about twice the bubble departure diameter. The heat transfer during bubble growth and departure was negligible.

Sydney and Edwards (1956) proposed the existence of a microlayer (thin liquid layer) at the wall trapped by the growing bubble. This layer could evaporate and transfer a large amount of energy. Subsequent work by Moore and Mesler (1961) and Hendricks and Sharp (1964) found that the wall temperature decreased sharply during the bubble growth and supported Sydney and Edwards's thin liquid layer theory. Moreover, Cooper and Lloyd (1969) found that an initial sharp drop in temperature as the microlayer evaporated with the wall temperature increasing somewhat after formation of a dry spot was followed by a small drop in temperature and subsequent recovery as the liquid re-wetted the surface during the bubble departure. The heat flux calculated from the temperature-time curves indicated a large heat transfer rate during the microlayer evaporation with a much smaller heat transfer rate during rewetting of the surface. The contact line heat transfer model was proposed by Stephan and Hammer (1994) who assumed that the evaporation of a thin liquid meniscus at the threephase contact line is the main heat transfer mechanism during nucleate boiling heat transfer.

Microlayer evaporation theory has prevailed for several decades as the dominant heat transfer mechanism during nucleate boiling. During the last decade, availability in more advanced diagnostic tools such as microfabrication, advanced data acquisition, and high-speed imaging technologies allows more advanced experimental methods, which thus contributes to great advancements in fundamental research of boiling phenomena. Demiray and Kim (2004) found that the bubble growth for both subcoolings was primarily due to the energy transfer from the superheated liquid layer and relatively little was due to the wall heat transfer during the bubble growth process. Oscillating bubbles and sliding bubbles were also observed in highly subcooled boiling conditions. Transient conduction and/or microconvection were the dominant heat transfer mechanisms in the above cases. By maintaining the microheaters at constant heat flux conditions, Myers et al. (2005) found that the data indicated that most of the energy required for bubble growth came from the superheated layer around the bubble. Microlayer evaporation and contact line heat transfer accounted for no more than $23 \%$ of the total heat transferred from the surface. The dominant heat transfer mechanism was transient conduction into the liquid during the bubble departure. 


\subsection{Coalescence of Bubbles}

In the high-flux nucleate boiling regime, the heat transfer is much higher than other regimes, which explains why the nucleate boiling process is a highly effective heat transfer mode. The suggested theory is that as temperature of the heater surface increases from the onset of nucleate boiling, more nucleation sites are activated leading to more coalescence of bubbles on the heater surface, which further increases the heat flux until the critical heat flux point (CHF) is reached. Experimental observations of bubble coalescence were performed by Haddad and Cheung (1998) during nucleate boiling on a downwardfacing hemispherical surface and by Ohnishi et al. (1999) in a lowgravity environment. Bonjour et al. (2000) reported a study of the coalescence phenomenon (merging of two or more bubbles into a single larger one) during pool boiling on a duraluminium (AU4G) vertical heated wall. They investigated various boiling curves characterizing boiling (with or without coalescence) for three artificial nucleation sites which are spaced at variable distances apart. In their experiment, the heat flux ranges from 100 to $900 \mathrm{~W} / \mathrm{cm}^{2}$ and the wall superheat from 5 to $35 \mathrm{~K}$. They pointed out that the coalescence of bubbles results in higher heat transfer coefficients than single-site boiling. They also showed that coalescence results in a decrease in the bubble departure frequency. It has been long thought that bubble-bubble coalescence plays an important, if not dominant, role in the high heat flux nucleate boiling regime and during the $\mathrm{CHF}$ condition as well. A mechanistic model based on the bubble coalescence in the wall bubble layer was proposed by Kwon and Chang (1999) to predict the critical heat flux over a wide range of operating conditions for the subcooled and low quality flow boiling. Comparison between the predictions from their model and the experimental CHF data shows a good agreement over a wide range of parameters. Sakashita and Kumada (1993) proposed that the CHF is produced by the dryout of a liquid layer formed on the heating surface. They also suggested that a liquid macrolayer is formed due to the coalescence of bubbles for most boiling systems, and that the dryout of the macrolayer is controlled by the hydrodynamic behavior of coalesced bubbles on the macrolayer. Based on these considerations, a new CHF model is proposed for saturated pool boiling at higher pressures. In the model, they suggest that a liquid macrolayer is formed due to the coalescence of secondary bubbles formed from the primary bubbles. The detachment of the tertiary bubbles formed from the secondary bubbles determines the frequency of the liquid macrolayer formation.

Because of the complicated flow and heat transfer mechanisms, the research on coalescence has not progressed very fast in both experimental and theoretical fronts. Coalescence of bubbles on a surface is a highly complicated process that involves a balance among surface tension, viscous and inertia forces. This phenomenon is intrinsically a fast transient event. Due to the above reasons, the research in bubble coalescence and its effect on boiling heat transfer have been rather limited. The microheater array system, based on MEMS technology, was first adopted by Rule and Kim (1999) for microscopic boiling heat transfer study. The system featured a square array of 96 micro-heaters as shown in Fig. 2(a). Each microheater with a size of $0.27 \mathrm{~mm} \times 0.27 \mathrm{~mm}$ is independently controlled. Each microheater as shown in Fig. 2(b) is made of platinum filaments of 2 $\mu \mathrm{m}$ in width and submicron in thickness deposited on quartz substrate with a serpentine pattern. The control unit is capable of setting and maintaining either the constant temperature or the constant heat flux level for each microheater and then monitoring the other during the experiment. Because of the microscale infrastructure, the thermal inertia is negligibly small. With a sampling frequency up to 10,000 Hertz, the time and space resolved measured data are highly accurate.

Chen and Chung (2002, 2003a) used a similar micro heater system to provide the first quantitative measurement of micro-scale boiling heat transfer characteristics for a single bubble and also for coalescing duel and multiple bubbles on the microheater array surface. As reported

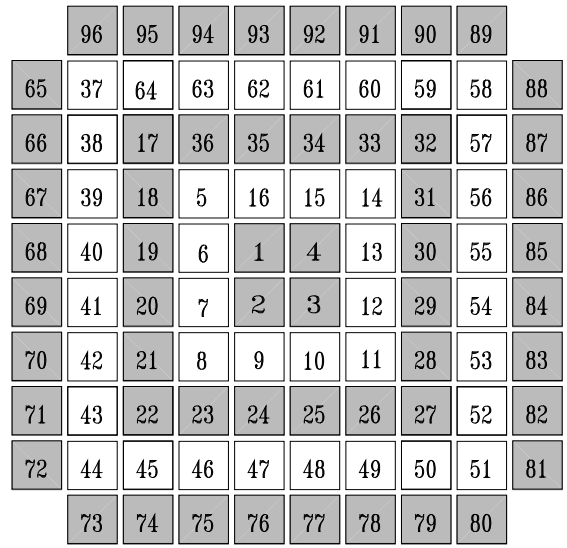

(a) The arrangement of 96 micro-heaters

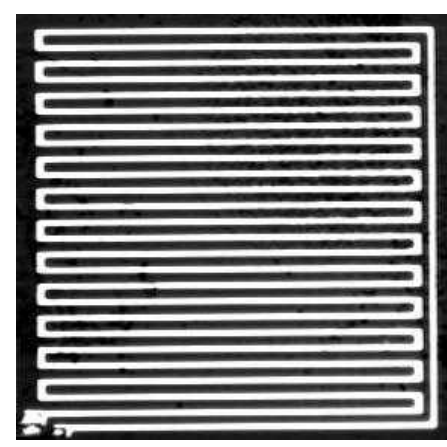

(b) Heater Filament Pattern

Fig. 2 Micro-Heaters Array.

in Chen and Chung (2002, 2003a), a typical ebullition cycle for a single bubble is composed of two basic stages as shown in Fig 3: (1) bubble nucleation (Step A) which takes place spontaneously with the departure of the proceeding bubble (Step F), and (2) bubble growth (Steps B. C, $\mathrm{D}$ and $\mathrm{E}$ ). There is only one heat flux spike for a single bubble ebullition cycle that is the result of the combined bubble departure and nucleation process. While the ebullition cycle for the case of bubblebubble coalescence, the cycle is characterized by the following stages as shown in Fig. 4 in terms of the heat flux histogram: (1) departure of the proceeding coalesced bubble with spontaneous nucleation of the new single bubbles (Step A); (2) growth of two single bubbles separately (Step B); (3) coalescence of the dual bubbles (Step C); and (4) growth of the coalesced bubble (Steps D and E). As seen from the heat flux data, the coalescence case is associated with two heat flux spikes for an ebullition cycle as compared to just one spike for a single bubble case. In general, for each ebullition cycle, the cycle with the coalescence produces $25-70 \%$ more heat transfer than that of the single bubble case. This enhanced heat transfer is solely due to the coalescence process that creates contact line movement and rewetting of the heater surface by colder liquid and also induces turbulent mixing effects. The enhancement is proportional to the ebullition cycle frequency and heater superheat. It was also found that the longer the heater separation distance is, the higher the heat transfer rates would be enhanced. It was also determined that the boiling heat transfer is closely associated with the bubble's contact line movement and dry area on the heater surface. The heat transfer rate during bubble growth after coalescence is larger than that before coalescence, which is due to the fact that the MCL length of a coalesced bubble is larger than the total of two single bubbles before merging. The Florida group was the first and the only to report in the open literature on quantitative measurement of the heat transfer enhancement due to the coalescence of bubbles in nucleate boiling using constant temperature micro heaters. 


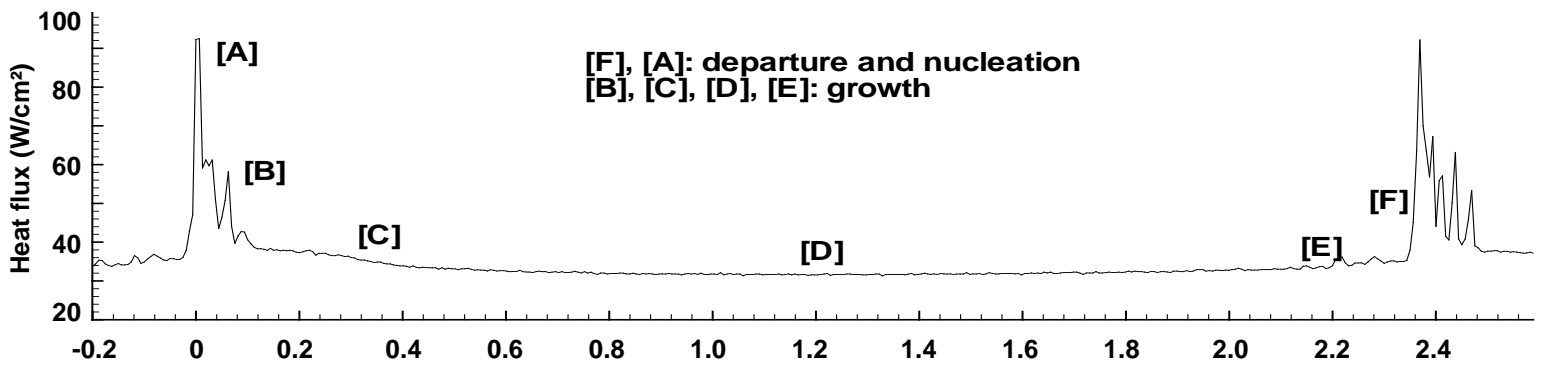

(a)

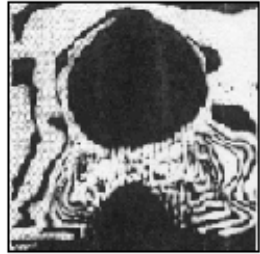

A

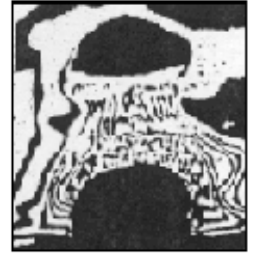

B

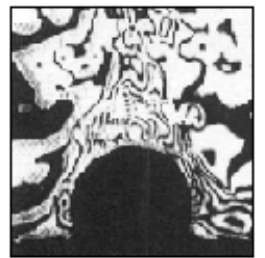

C

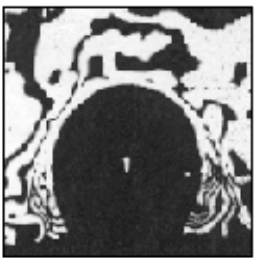

$\mathrm{D}$

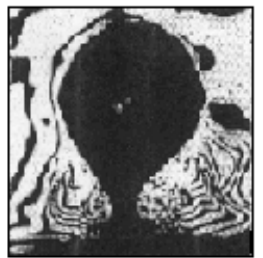

E

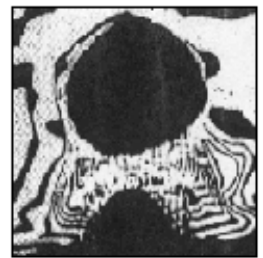

F

(b)

Fig. 3 Single Bubble Ebullition Cycle, (a) experimental data (Chen and Chung, 2003a) and (b) bubble ebullition image (Nordmann and Mayinger, 1981).

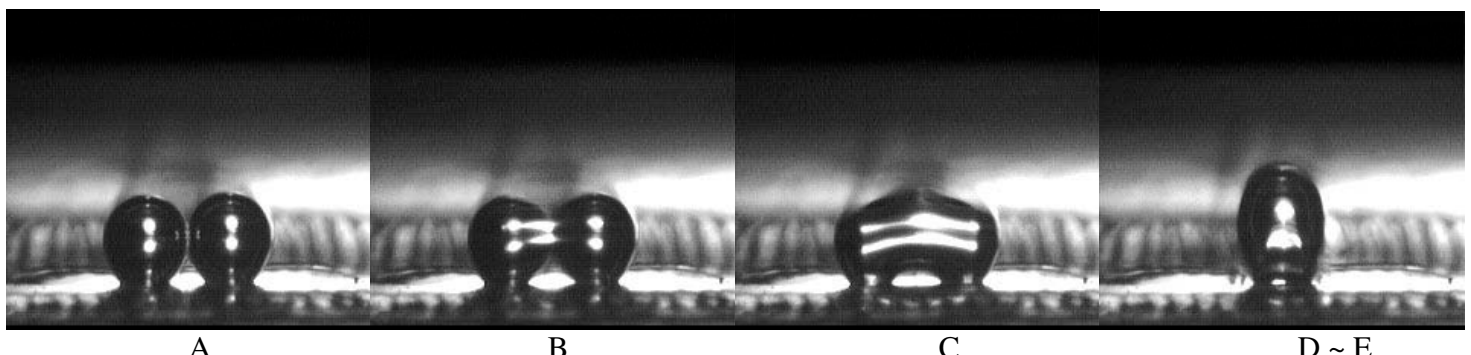

(a)

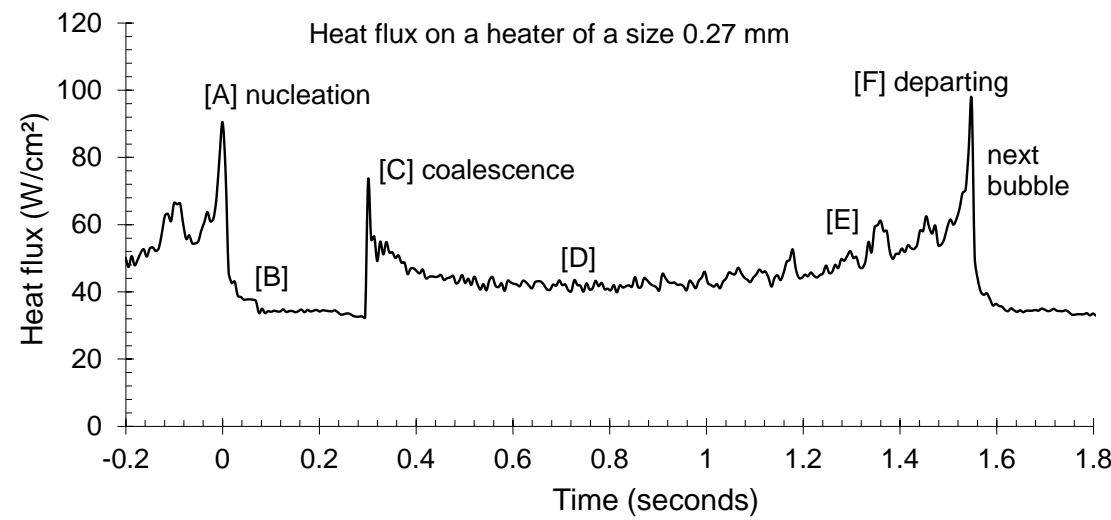

(b)

Fig. 4 (a) Visualization of coalescence of two bubbles generated on two heaters and (b) corresponding heat flux on one heater.

In a numerical study, Yang et al. (2000) performed a numerical study to investigate the characteristics of bubble growth, detachment and coalescence on vertical, horizontal, and inclined downward-facing surfaces. The FlowLab code, which is based on a lattice-Boltzmann model of two-phase flows, was employed. Macroscopic properties, such as surface tension and contact angle, were implemented through the fluid-fluid and fluid-solid interaction potentials. The model predicted a linear relationship between the macroscopic properties of surface tension and contact angle, and microscopic parameters. Hydrodynamic aspects of bubble coalescence are investigated by simulating the growth and detachment behavior of multiple bubbles generated on horizontal, vertical, and inclined downward-facing surfaces. For the case of a horizontal surface, three distinctive regimes of bubble coalescence were represented in the lattice-Boltzmann simulation: lateral coalescence of bubbles situated on the surface, vertical coalescence of bubbles detached in a sequence from a site, and lateral coalescence of bubbles, detached from the surface. Multiple coalescences was predicted on the vertical surface as the bubble detached from a lower elevation merges with the bubble forming on a higher site.

Chen and Chung (2003b) and Chen et al. (2004) examined the effects of heater size on the boiling characteristics. They concluded that the boiling curve obtained from the microheater is composed of two 
regimes which are separated by a peak heat flux. It is suggested that in the lower superheat regime, the boiling is dominated by liquid rewetting and micro-layer evaporation, while in the higher superheat regime, conduction through the vapor film and micro-convection play the key heat transfer role as the heater is covered by vapor all the time. In general, boiling on microheaters is characterized by larger bubble departure sizes, smaller bubble growth rates due to the dryout of microlayer as the bubble grows, and higher bubble incipience superheat. As the heater size decreases, the boiling curve moves towards higher heat fluxes with corresponding higher superheats. The unique heat transfer processes associated with boiling on a microheater are considerably different from those typically observed during boiling on a macroscale heater.

\subsection{Boiling on Mini Heaters and Effects of Heater Size}

Immersion cooling of electronic devices sparks interests of boiling on small heaters. Baker (1973) studied boiling of R113 on heaters with sizes of $20 \times 10 \mathrm{~mm}^{2}, 9.8 \times 4.9 \mathrm{~mm}^{2}$, and $4.6 \times 2.3 \mathrm{~mm}^{2}$. Their results showed that at a given superheat the heat flux increases with decreasing heater size. For example, at a superheat of $10 \mathrm{~K}$, the heat fluxes are $2.8 \times 10^{3}, 1.9 \times 10^{4}$ and $4.2 \times 10^{4} \mathrm{~W} / \mathrm{m}^{2}$ for heater sizes of $20 \times 10 \mathrm{~mm}^{2}$, $9.8 \times 4.9 \mathrm{~mm}^{2}$, and $4.6 \times 2.3 \mathrm{~mm}^{2}$, respectively. The effect of heater size on critical hat flux was later investigated by Gogonin and Kutaleladze (1977) and they did not observe any measurable effect of the heat size on critical heat flux when the boiling surface was placed to face upward. However, when the surface was placed to face downward, they found that the critical heat flux was measured to increase with decreasing heater size. This increase in critical heat flux was also observed by Ishigai et al. (1961) and Granovskii et al. (1994). Measurements by both Lienhard et al. (1973) and Saylor et al. (1989) showed that the critical heat flux remained relatively constant for heater sizes greater than a threshold value at which the critical heat flux increases with decreasing heat size for the upward-facing boiling surfaces. The effect of heater size on boiling performance prior to critical heat flux was investigated by Park and Bergles (1988); their results showed that boiling performance is not sensitive to heater size. Furthermore, boiling experiments of FC-72 on heaters of different sizes $\left(25 \mathrm{~cm}^{2}, 4 \mathrm{~cm}^{2}\right.$, and $1 \mathrm{~cm}^{2}$ ) performed by Rainey and You (2001) and Chang and You (1996) showed that boiling heat transfer is only slightly inversely proportional to heater size. However, they found the boiling incipient superheats are 25-40K, 20-35K and 16-17K for heaters of 1 $\mathrm{m}^{2}, 4 \mathrm{~m}^{2}$ and $25 \mathrm{~m}^{2}$, respectively. They also found the critical heat flux increases with decreasing heater size. Hijikata et al. (1997) investigated boiling on micro-scale heaters and found that the optimum thickness of the surface-deposited layer to enhance heat removal from the heater in order to obtain the best cooling effect for a semiconductor. The square heaters they used were $50 \mu \mathrm{m}$ and $100 \mu \mathrm{m}$ in size. They claimed that the conduction in the deposited layer dominates the heat transfer due to the small sizes of the heater area. They also presented the nucleate boiling curves for the two heater sizes and different deposited layer thicknesses. By using a temperature control scheme, Rule and Kim (1999) and Chen and Chung (2002, 2003a) performed boiling of FC-72 on constant temperature small heaters, respectively of sizes $2.7 \times 2.7$ $\mathrm{mm}^{2}$ and $0.27 \times 0.27 \mathrm{~mm}^{2}$.

Chen and Chung (2003b) and Chen et al. (2004) further examined the effects of heater size on the boiling characteristics. They concluded that the boiling curve obtained from the microheater is composed of two regimes which are separated by a dividing wall superheat. It is suggested that in the lower superheat regime, the boiling is dominated by liquid rewetting and micro-layer evaporation, while in the higher superheat regime, conduction through the vapor film and microconvection play the key heat transfer role as the heater is covered by vapor all the time. In general, boiling on microheaters is characterized by larger bubble departure sizes, smaller bubble growth rates due to the dryout of microlayer as the bubble grows, and higher bubble incipience superheat. As the heater size decreases, the boiling curve moves towards higher heat fluxes with corresponding higher superheats. The unique heat transfer processes associated with boiling on a microheater are considerably different from those typically observed during boiling on a macroscale heater.

A comparison of boiling curves on different heater sizes given by Chen and Chung (2003a) is reproduced in Fig. 5. The effect of heater size on the critical heat flux is plotted in Fig. 6 with data from Chen and Chung (2003a), Rule and Kim (1999), Rainey and You (2001), and Chang and You (1996) for square heater sizes of $270 \mu \mathrm{m}, 2700 \mu \mathrm{m}, 1$ $\mathrm{cm}$ and $5 \mathrm{~cm}$, respectively. .

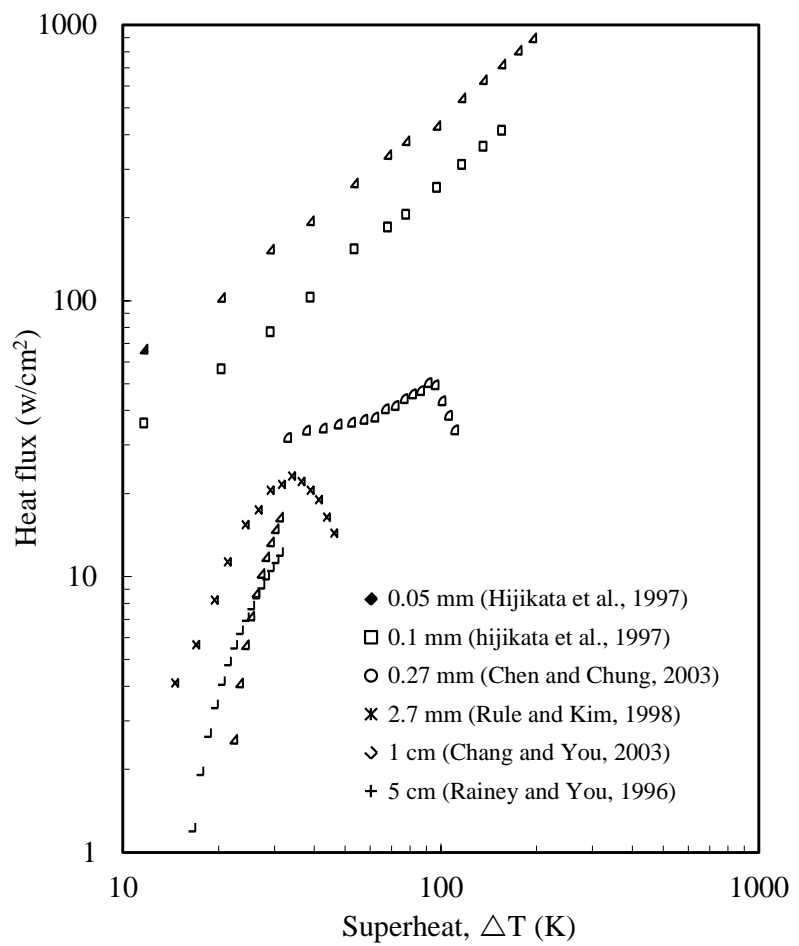

Fig. 5 Boiling curves for boiling on different heat sizes (Chen and Chung, 2003a).

\subsection{Nucleation on a Microheater}

Applications of micro-technology often utilize components or systems with microscale fluid flow and heat transfer. As the size of an individual component shrinks and the length scale decreases drastically, the associated transport mechanisms go beyond those covered by the traditional theories and understanding. The development of new theories and the fostering of up-to-date physical understanding have fallen behind the progress of micro machining and manufacturing.

Gad-el-Hak (1999) gave a review on the fluid mechanics of microdevices. He concluded that the technology is progressing at a rate that far exceeds our understanding of the transport physics in micro-devices. Therefore the study of micro-scale transport has become an integral part of not only understanding the performance and operation of miniaturized systems, but also designing and optimizing new devices. One of many such applications is bubble-actuated microsystems such as bubble-actuated micropump (Liu and Cheng, 2007), laserjet printers (Nielsen, 1985), and bubble-actuated optical switches in telecommunication applications (Uebbing et al., 2006). For such applications, the bubble produced from a microheater should be designed to function in a stable and controllable manner. Therefore, it is important to understand the bubble formation mechanisms on microheaters so that they may be optimally designed and operated. A number of previous studies have investigated the bubble formation mechanism. Iida et al. (1994) used a $0.1 \mathrm{~mm} \cdot 0.25 \mathrm{~mm} \cdot 0.25 \mathrm{~mm}$ platinum film heater subject to rapid heating (maximum 93 - $106 \mathrm{~K} / \mathrm{s}$ ). The heater temperature was correlated to its electrical resistance. The 
temperature measured at the bubble nucleation suggested the occurrence of homogeneous bubble nucleation in their experiment. Lin et al. (1998) used a $50 \mu \mathrm{m} \times 2 \mu \mathrm{m} \times 0.53 \mu \mathrm{m}$ polysilicon resistance heater to produce microbubbles in Fluorinert liquids. Using a computational model and experimental measurements, they concluded that homogeneous nucleation occurs on the microline heater.

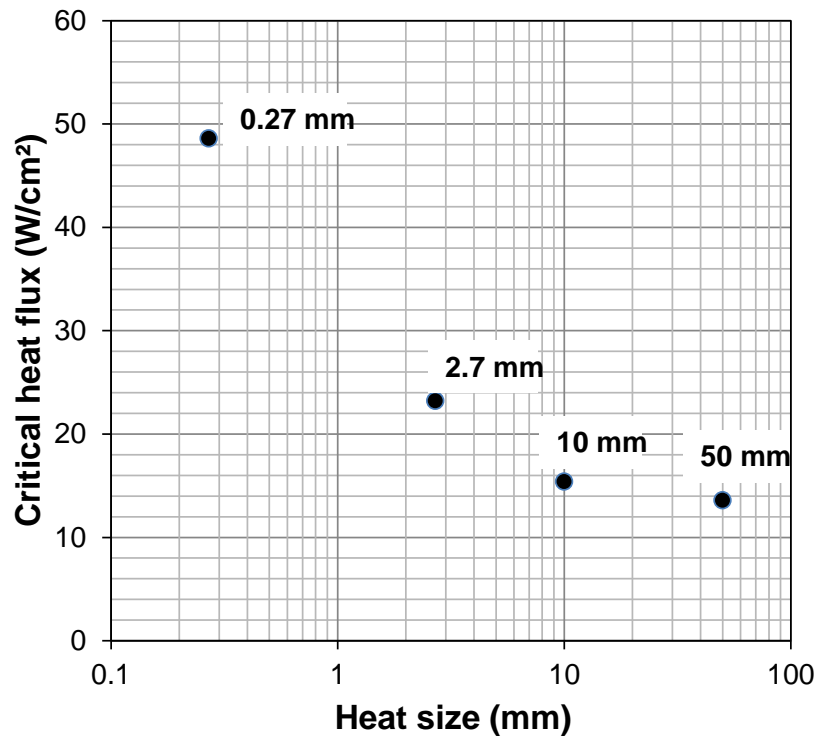

Fig. 6 Effect of heater size on boiling critical heat flux (Chen and Chung, 2003a).

Avedisian et al. (1999) performed experiments on a heater used in commercial thermal inkjet printers that comprises a mixture of tantalum and aluminum $(64.5 \mu \mathrm{m} \times 64.5 \mu \mathrm{m} \times 0.2 \mu \mathrm{m})$ by applying voltage pulses of short durations. At extremely high heating rates (2.5 - 108 $\mathrm{K} / \mathrm{s}$ ), homogeneous nucleation at the heater surface was suggested as the mechanism for bubble formation, with the nucleation temperature increasing as the heating rate was increased. Zhao et al. (2000) used a similar thin-film microheater, $100 \mu \mathrm{m} \times 110 \mu \mathrm{m}$ in size, to investigate the vapor explosion phenomenon. They placed the microheater on the underside of a layer of water and the surface temperature of the heater was rapidly raised (about $106 \mathrm{~K} / \mathrm{s}$ ) by electrical pulses of short durations. By measuring the acoustic emissions using a pressure transducer from an expanding volume of a vapor bubble, the dynamic growth of the vapor microlayer was reconstructed. The maximum pressure inside the vapor volume of 7 bar was calculated from the measured acoustic pressure. The heating rates in these studies (Iida et al., 1994; Lin et al., 1998; Avedisian et al., 1999; Zhao et al., 2000) were extremely high, and are believed to be important for the homogeneous nucleation process. Recently, Balss et al. (2005) investigated the effect of surface hydrophobicity on bubble incipience using a pulse-heated microheater and a novel laser strobe microscopy technique. Imaging rates of over 10 million frames/s were achieved. It was found that bubble nucleation requires a higher superheat and occurs at an earlier time for hydrophilic surfaces compared with those that are hydrophobic.

It should be noted that a constant temperature condition is useful for identifying the nature of boiling incipience because the degree of superheat is a controlling parameter. With a constant temperature microheater, bubble incipience on a very smooth microscale heater (approximately $10 \mathrm{~nm}$ rms of roughness) is further investigated by Chen et al. (2006) to establish that bubble incipience under these conditions is indeed a homogeneous process and to elucidate the mechanics of the process. The flow visualization under side and bottom views and the simultaneous heat flux measurement provide sufficient information to allow a clear identification of the highly transient bubble incipience process. The experiments have been performed on a resistance heater of the size 0.27 by $0.27 \mathrm{~mm}$, coated with silicon dioxide. The incipience process was visualized from the side and the bottom of the semi-transparent heater, and the transient heat transfer was simultaneously recorded.

\subsection{Boiling Enhancement with Nanotechnologies 3.5.1 Nano-fluids}

Nanofluids are heat transfer fluids mixed with nanoparticles that are uniformly and stably suspended in the host liquid. Addition of nanoscale solid particles in liquids such as water has been shown to substantially expand the cooling thresholds for phase-change heat transfer that has been the main mode of heat removal from nuclear reactor cores (Buongiorno, 2006; Buongiorno et al. 2008). It was reported that up to $200 \%$ enhancements of boiling critical heat flux at modest nanoparticle concentrations of less than $0.1 \%$ by volume (Buongiorno, 2006). Since the critical heat flux is the upper limit of nucleate boiling, such improvement offers a potential for a breakthrough in cooling capacity for power systems that have relied on boiling heat transfer for system operations such as advanced nuclear reactors. A study by Buongiorno et al. (2008) predicts that with just a $32 \%$ increase in the critical heat flux, the current nuclear reactor power density would go up by $20 \%$. Therefore the enhancement potential for future advanced nuclear reactors could be much higher. The effect of nanoparticles on boiling heat transfer is thought to be due to a change in wetting characteristics by the nanofluids and the formation of a porous layer on the heating surface. Also, the relative size of the particle with respect to the surface roughness seems to be of significant importance.

The concept of nanofluids has been advanced remarkably by Choi (1995) who showed a potential for substantial augmentation of heat transport in suspensions of copper or aluminum nanoparticles in water or other liquids, which was found later to be attributed to the increase in the equivalent thermal conductivity of the base fluid (Lee et al., 1999; Choi et al., 2001; Eastman et al., 2001). By using the technique of molecular dynamics simulation, Sarkar and Selvam (2007) compared thermal conductivity of base fluids and nanofluids with nanoparticle loadings and showed that the increase in thermal conductivity was due to an increased motion of liquid atoms in the presence of nanoparticles. You et al. (2003) measured boiling heat transfer with nano-particles $\left(\mathrm{Al}_{2} \mathrm{O}_{3}\right)$ and their results as shown in Fig. 7 showed that the critical heat flux is increased dramatically, but there is no significant enhancement for boiling in the nucleate boiling regime reflected by the boiling curve. However, Das et al. (2003) observed that the presence of nano-particles deteriorates the boiling performance systematically with an increase in particle concentration as shown in Fig. 8, which was also observed by Kim et al. (2007). Das et al. (2008) later on commented that deterioration in heat transfer coefficient was mainly observed at higher particle concentrations (4-16\% by weight) and enhancements mainly at lower particle concentrations $(0.32-1.25 \%$ by weight). The experimental study of boiling of three different nanofluids (alumina, zirconia and silica nanoparticles with water being the base fluid) performed by Kim et al. (2007) indicated that the enhancement in critical heat flux (CHF) is achieved at modest nanoparticle concentrations ( $<0.1 \%$ by volume) that is attributed to buildup of a porous layer of nanoparticles on the heater surface occurred during nucleate boiling. This layer significantly improves the surface wettability, as shown by a reduction of the static contact angle on the nanofluid-boiled surfaces compared with the pure-water-boiled surfaces.

For boiling of nanofluids with large-size nanoparticles, the deposition of nanoparticles on the heater surface during boiling was also observed by Jo et al. (2009). Comparing with boiling of the basefluid, the boiling curve for boiling nano-fluids was shifted toward the higher-temperature regime, indicating that the boiling heat transfer is deteriorated while the CHF was measured to increase. Moreover, the $\mathrm{CHF}$ in the boiling of nanofluids increases as the size of the nanoparticles was decreased. 


\subsubsection{Nano-structured surfaces}

Another potential heat transfer breakthrough could come from nanostructured boiling surfaces such as those coated with nano carbon tubes. These nano-surface textures have the potential to alter the surface properties such as wettability and thermal conductivity. Also they might provide more favorable nucleation sites for boiling and condensation initiations. Boiling heat transfer enhancement from surfaces of nano wires has been experimentally observed in recent studies by Chen et al. (2008, 2009). However, experimental results obtained by Launay et al. (2006) indicated that the use of the CNT-enabled, purely nanostructured interfaces appeared to improve boiling heat transfer only at very low superheats, compared with the smooth surfaces. Nanostructures only promote bubble nucleation, but not departure. At high heat fluxes, bubble departure characteristics may be degraded due to micro/nano structures. Thus no enhancement was observed at high heat fluxes. They also measured pool boiling of PF5060 and DI water on 3D micro-structured (staggered cross-meshing) surfaces, and obtained the maximum (not critical) heat fluxes of 27 and $130 \mathrm{~W} / \mathrm{cm}^{2}$, respectively.

Ahn et al. (2009) and Sathyamurthi et al. (2009) reported experimental results of pool boiling in the PF5060 fluid on silicon heaters coated with vertically aligned, multi-walled carbon nanotubes (MWCNTs). Using NWCNTs of layer thicknesses of $9 \mu \mathrm{m}$ (Type A) and $25 \mu \mathrm{m}$ (Type B), they found that the critical heat flux was increased by $62 \%$ and $58 \%$, respectively. With the Type B heater, the minimum heat flux at the Leidenfrost point was increased by $150 \%$. There were no significant differences in the film boiling rates with both heater types. Carbon nanotubes would function as a nanoscale heat pipe and inside these tubes, nanoscale liquid films evaporate from one side of the channel and condense on the opposite side wall surfaces. It is believed that the nano-sized film evaporation contributes to the super-high heat flux transport rates.

While pool boiling on surfaces with nano-structures has been performed extensively, convective boiling on these surfaces has not received enough attention. Recently Hsieh and Lin (2010) reported subcooled convection boiling enhancement in microchannels coated with a $2 \mu \mathrm{m}$ thick diamond film. The internal surfaces were implemented with structured cavities to promote nucleation. Nanofluids of FC-72 mixed with multi-walled carbon nanotubes were used as the coolant. The main results are the maximum heat transfer enhancement of $90 \%$ and more than an order of magnitude increase in the critical heat flux.

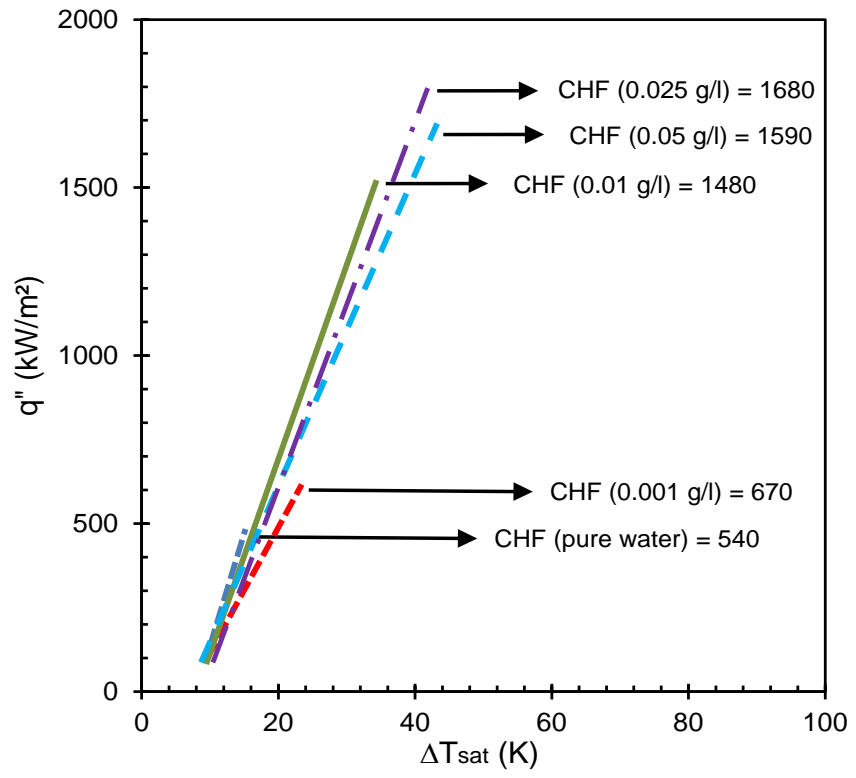

Fig. 7 Enhancement of critical heat flux during pool boiling (You et al. 2003).

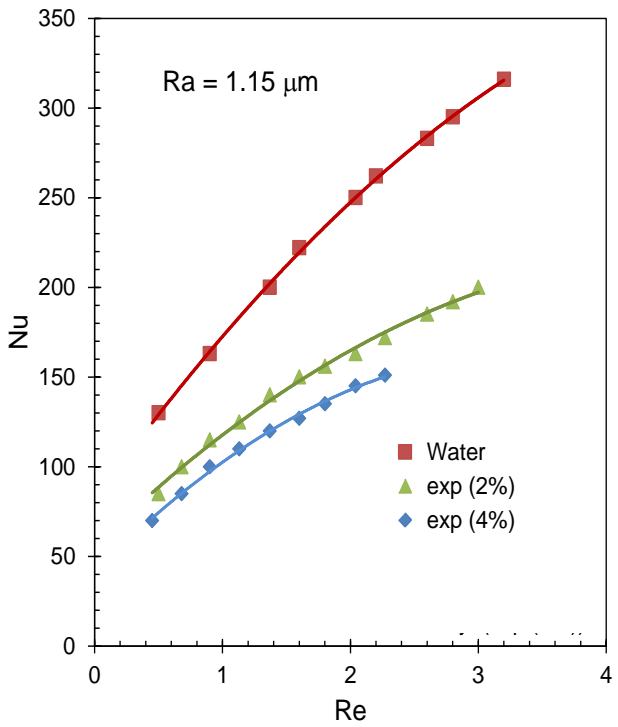

Fig.8 Boiling heat transfer deterioration (Das et al., 2003).

\section{THEORETICAL/NUMERICAL DEVELOPMENT}

Nucleate boiling process is a complex phenomenon which is multi-scale in nature. Owing to the dependency on various parameters, such as nucleation sites, bubble growth rates, bubble release frequency, temperature field in liquid/solid, etc., and their non-linear dependency on the boiling process, no universal model has been proposed which can predict nucleate boiling for any combinations of fluid and surface involved. Since the past few decades, empirical correlations have been introduced; however, predictions from these correlations are valid only for the limited range over which the supporting data have been obtained (Dhir, 2006). Since, empirical correlations do not provide fundamental physical understanding of nucleate boiling, it is essential to examine the underlying multi-scale nature of the process which gives rise to the macroscale phenomenon of boiling we observe. The multi-scale behavior occurs at the three-phase contact line of a bubble, as seen in Figure 1 . The contact line region is comprised of non-evaporating thin film region, evaporating thin film region and intrinsic meniscus region. The non-evaporating region is on the length scale of nanometers, whereas the evaporating and intrinsic meniscus regions have the characteristic dimension of micrometers and higher. Thus, the contact line region can be divided into nano- and micro- regions as in Figure 1b. In the past decade, these two regions have been simulated separately; the micro- region using continuum mechanics, and the nanoregion using molecular dynamics simulations. The following sections review the recent advancements in numerical simulations of these multi-scale regions.

\subsection{Micro-region Modeling using Continuum Mechanics}

Lee and Nydahl (1989) applied the axi-symmetric Navier-Stokes and energy equations to a nucleate bubble in saturated pool boiling, and solved numerically from inception to departure. Major assumptions included no-slip velocity boundary condition around the bubble, negligible free convection and specified bubble and microlayer shape. For the conditions simulated, the microlayer proved to be the dominant mechanism; it provided 90 percent of the energy for bubble growth, and 87 percent of the overall enhanced heat transfer. Ma and Pan (1999) investigated nucleate boiling heat transfer, characterized by the existence of macrolayer. Two-region equations were proposed to simulate both thermo-capillary driven flow in the liquid later (via continuity equations, axial and radial momentum equation, energy equation) and heat conduction in the solid wall. The numerical simulation showed several multi vorticies in the macrolayer. These 
vortex cells, induced in the vapor-liquid interface of the macrolayer due to the thermo-capillary driven flow, were shown to efficiently transfer heat away from the wall. Son (2001) proposed a numerical method based on a level set technique for capturing the phase interface which included the effect of phase change at the interface as well as to achieve mass conservation. The modified level set method was applied for numerical simulation of bubble rise and growth in a stationary liquid. Ye et al. (2001) developed a fixed-grid direct numerical simulation method for studying single bubble deformation and phase change. The mass, momentum, and energy balance conditions were satisfied at the interface, and the interface was considered to be sharp. The field equations were solved numerically using a finite volume method based on the fractional step method. The proposed algorithm was capable of accurately handling wide ranges of $\mathrm{Re}$, We, Ja, Pe, and property jumps between phase boundaries. It was shown that for a stationary bubble growing in a superheated liquid, the growth rate approaches $R(t) \propto t^{1 / 2}$. The effect of bubble motion causes the growth rate to accelerate, and the density ratio becomes an important parameter as the vapor density drops below a certain level. Mukherjee and Dhir (2004) numerically studied bubble dynamics and associated wall heat transfer during lateral bubble merger. They solved the incompressible Navier-Stokes equation and captured the liquid-vapor interface using the level set formulation. Mergers of two bubbles, three bubbles in a line and three bubbles in a plane were simulated assuming axisymmetry. The contact angle between the wall and the bubble was taken to be constant throughout the simulation. The authors acknowledge the fact that the results are sensitive to contact angle. Liao et al. (2004) presented a physical model to predict the early stage bubble growth in saturated heterogeneous nucleate boiling. The microlayer was taken to be in the form of a wedge. The structure of the thin unsteady liquid thermal boundary layer is revealed by the asymptotic and numerical solutions. The authors find that in some cases, the heat transfer from the thin unsteady thermal boundary layer near the rapidly growing bubble can be larger than that from the microlayer. Shin et al. (2005) simulated the complex transport and coupled interface dynamics of nucleate boiling in three-dimensions using the Level Contour Reconstruction Method. The effect of nucleation site density was included in the numerical model by changing the surface area for a single nucleate bubble corresponding to the wall temperature. The three-dimensional simulations demonstrated more accurate agreement with published Nusselt number correlations than did the two-dimensional simulations. However, the simulation did not incorporate models for microlayer evaporation and contact line dynamics which are essential to the heat transfer mechanism. Tomar et al. (2005) used the coupled level-set and volume-of-fluid method to simulate bubble growth in water at near critical pressure for different degrees of superheat. The coupled algorithm was said to conserve mass and capture the complicated interfaces very accurately. The effect of superheat and saturation pressure on frequency of bubble formation was analyzed. Genske and Stephan (2006) modeled the macro-region by solving the Navier-Stokes equation for both vapor and liquid phase using finite element method. The micro region was wedge shaped and moving mesh was used for free surface simulation. Flow inside and around a growing bubble and its influence on the overall heat transfer was considered. Mukherjee and Kandlikar (2007) used a static contact angle and dynamic contact angle models based on the contact line velocity and the sign of contact line velocity to numerically study the growth and departure of single vapor bubbles from a heated wall. The liquid-vapor interface is simulated using the level-set technique. The effect of microlayer evaporation at the bubble base was neglected. The authors concluded that correct motion of the contact line can be simulated when the dynamic contact angle is represented as a function of interface velocity. Son and Dhir (2008) numerically studied nucleate boiling at high heat fluxes by solving the equations governing conservation of mass, momentum and energy in the liquid and vapor phases. The interface was captured by using the level set method based on a sharp-interface representation, and the evaporative heat flux from the liquid microlayer was incorporated. Bubble growth and release was analyzed for both low and high wall superheats. A sample 3D calculations with a coarser grid was also performed which gave heat flux values about $40 \%$ lower than that for corresponding 2D case. Stephan and Fuchs (2009) developed a fully transient numerical model which allows describing the transient heat and fluid flow during the entire periodic cycle of a growing, detaching and rising bubble including the waiting time between two successive bubbles from a single nucleation site. The model contains a multiscale approach ranging from the nanometer to the millimeter scale for the detailed description of the relevant local phenomena. The authors concluded that the assumption of a constant and homogeneous wall surface temperature that is used in many modeling approaches does not hold for an accurate description, and that the capability of the wall and liquid to temporarily store energy is an important property of the boiling system that should be considered in numerical models as well as in boiling correlations.

Numerical simulation of heterogeneous boiling was recently done using the lattice Boltzmann method (Hazi and Markus, 2009). Simulation results demonstrated that the bubble departure diameter and bubble release frequency are proportional to $\mathrm{g}^{-1 / 2}$ and $\mathrm{g}^{3 / 4}$, respectively, where $\mathrm{g}$ is the gravitational acceleration. The bubble release frequency showed exponential decay with the static contact angle. Wu and Dhir (2010) employed a numerical procedure, coupling the level-set function with the moving mesh method, to simulate subcooled nucleate boiling under various gravity levels. The applied numerical procedure was validated by comparing the results of bubble-growth history including bubble departure diameter with data from experiments. The effect of subcooling on bubble size was found to be more pronounced under microgravity than under earth-normal gravity. The rate of heat transfer around the bubble decreased with reduction in gravity for a given subcooling due to stretching of length and time scales. Lee et al. (2010) performed analysis of bubble growth and formation during nucleate boiling on a horizontal surface with three types of cavities: truncated conical cavity, cylindrical and conical cavity. A numerical method was presented for this purpose where a sharp-interface level-set method for two-phase flows was modified to include the effect of phase change on the liquid-vapor interface and to treat the contact angle and microlayer heat flux on the immersed solid surface of microstructures. The simulation demonstrated that the cavity depth is one of the important parameters determining the existence of nucleate boiling and the truncated conical cavity was found to be more effective for bubble formation in nucleate boiling compared to the cylindrical and conical types of cavities.

\subsection{Nano-region Modeling using Molecular Dynamics Simulations}

Recently a few researchers attempted to observe nano-bubble nucleation using molecular dynamics simulations. The studies were associated with varying system pressure by using metastable liquid, increasing the nanochannel volume and thermally contracting the liquid by lowering the temperature. The nucleation occurs when the pressure reached the spinodal line. Maruyama and Kimura (2000) simulated heterogeneous nucleation of vapor bubble on a solid surface using molecular dynamics in a nanochannel. Liquid argon was placed between parallel solid platinum surfaces and gradually expanded until a vapor bubble was nucleated. The wettability of the lower surface was varied by changing the potential parameter between argon and solid molecule. Wu and Pan (2003) studied bubble nucleation in a homogeneous Lennard-Jones liquid under heating with a constant mean negative pressure using molecular dynamics. Velocity-scaling temperature control is used to raise the system temperature while the system volume is expanded to keep the mean pressure nearly constant. No solid surfaces were included in the simulation. Bubble nucleation is observed as the system pressure-temperature reaches the spinodal line. The authors find good agreement of nucleation rate between simulation and prediction from classical theory. Nagayama et al. (2006) carried out molecular dynamics simulations to examine the bubble behavior 
confined in a nanochannel with emphasis on nucleation phenomenon. A metastable liquid confined in a nanochannel with an inlet driving force was simulated. Nano-sized bubbles were observed wider different conditions of solid-liquid interfacial wettability. The authors also found that the vapor pressure inside the nano-bubble disagrees with the macroscopic Young-Laplace equation. Park et al. (2001) formed a similar bubble using molecular dynamics with the liquid initially in metastable condition. No solid surfaces were included in this simulation. The surface tension of the bubble, calculated from the density profile and from the normal and transverse components of pressure tensor, was found to increase very slightly with decrease of bubble radius. Schoen et al. (2005) investigated the phase transition of a simple liquid bounded between two parallel walls a few nanometers apart with molecular dynamics simulation. The authors used the fact that since some fluids (argon in their case) thermally contract on cooling, the lower wall temperature was reduced to the extent that the fluid started to crystallize starting from the bottom surface creating a "frozen" bubble in crystallized state. It was found that the confining walls primarily affect the crystallization process. The authors also noted that vapor nucleation in a liquid confined in a nanochannel cannot be achieved by solely increasing the temperature of the wall.

The above studies modeled the formation of nano-cavities in liquid using molecular dynamics. This has provided significant insight in the formation of nano-bubbles in nanoscale thermal systems, like nanochannels. However, these do not simulate the formation of the nonevaporating region and the interline region which are key towards understanding the fundamentals of nano-region of the three-phase contact line of a bubble. The interline region lies between the nonevaporating thin film region and the evaporation thin film region over which the film varies in thickness and curvature to accommodate the transition between the two regions. This is the thinnest portion of the meniscus over which vaporization can occur, and since it is the thinnest, it is also the location where the evaporation rate is the highest (Carey, 1992). Recently, Maroo and Chung (2008, 2009, 2010a, 2010b, 2011) simulated the formation of the non-evaporating and interline regions for the first time in published literature.

\subsubsection{Molecular dynamics simulation}

The computational domains in the simulations consist of Argon (Ar) atoms as the fluid and a surface made from platinum (Pt) atoms. Pt atoms are arranged in fcc (111) structure to constitute the Pt wall. The atomic interaction is governed by the modified Lennard-Jones potential as defined by Stoddard and Ford (1973):

$$
\begin{aligned}
U_{M L J}(r)=4 \varepsilon\left[\left\{\left(\frac{\sigma}{r}\right)^{12}\right.\right. & \left.-\left(\frac{\sigma}{r}\right)^{6}\right\}+\left\{6\left(\frac{\sigma}{r_{\text {cut }}}\right)^{12}\right. \\
& \left.\left.-3\left(\frac{\sigma}{r_{\text {cut }}}\right)^{6}\right\}\left(\frac{r}{r_{\text {cut }}}\right)^{2}-\left\{7\left(\frac{\sigma}{r_{\text {cut }}}\right)^{12}-4\left(\frac{\sigma}{r_{\text {cut }}}\right)^{6}\right\}\right]
\end{aligned}
$$

The above potential form is employed for both $\mathrm{Ar}-\mathrm{Ar}$ and $\mathrm{Ar}-\mathrm{Pt}$ interactions with the following values:

$$
\begin{aligned}
& \sigma_{A r-A r}=3.4 \times 10^{-10} \mathrm{~m}, \varepsilon_{A r-A r}=1.67 \times 10^{-21} \mathrm{~J}, \\
& \sigma_{A r-P t}=3.085 \times 10^{-10} \mathrm{~m}, \varepsilon_{\text {Ar-Pt }}=0.894 \times 10^{-21} \mathrm{~J} .
\end{aligned}
$$

The cutoff radius is $r_{c u t}$. The force of interaction can be calculated from the potential function as follows: $\vec{F}=-\nabla U$. The argon atoms are subjected to six boundaries, two in each of the $\mathrm{x}, \mathrm{y}$ and $\mathrm{z}$ directions. The boundaries in the $\mathrm{x}$ and $\mathrm{y}$ directions are periodic. The boundary conditions in the $\mathrm{z}$ direction can be periodic, mirror (i.e. elastic and adiabatic) boundary condition, or the presence of Pt wall(s) depending on the problem studied.

Pressure computations are verified in a computational domain consisting of a liquid layer surrounded by vapor in z-direction (as shown in Fig. 9(a)) for six different temperature cases (Maroo and
Chung, 2009). Periodic boundary condition is applied to all six boundaries. Temperature-density, pressure-density and surface tensiontemperature plots are shown in Figs. 9(b), 9(c) and 9(d) respectively, where the results from simulation are compared to experimental values from thermodynamic tables for argon. It can be seen that the values match well.

\subsubsection{Thermal wall model}

Many problems in the field of heat transfer require modeling the fluidsolid wall boundary condition across which the heat transfer takes place. Numerous models have been proposed and developed in literature to simulate wall-to-fluid heat transfer for molecular dynamics simulation; however, the biggest concern in these models is that the actual physics of the phase change heat transfer may not be properly depicted (Maroo and Chung, 2010a). Maroo and Chung (2008, 2010a) proposed a novel 'fluid-wall thermal equilibrium model' to simulate heat transfer from a surface to a fluid for molecular dynamics. The proposed model was verified by both state-dependent and timedependent properties. For the state-dependent verification (Maroo and Chung, 2008), physical properties of thermal conductivity and change in internal energy of liquid argon between two Pt walls were computed in molecular dynamics simulation, and shown to match well with thermodynamic tabulated values. For the time-dependent verification (Maroo and Chung, 2010a), temperature gradient in liquid argon placed between two Pt walls (one wall was heated while the other was cooled) was evaluated with time, and compared to the 1-D heat equation; good agreement was found in this analysis. Hence, this proposed model was used to simulate the evaporation of a thin film of argon placed on a $\mathrm{Pt}$ surface.

\subsubsection{Non-evaporating thin film region}

The simulation domain is a cuboid of dimensions $8.011 \mathrm{~nm} \times 8.011$ $\mathrm{nm} \times 18.961 \mathrm{~nm}$. A thin liquid argon film of $2 \mathrm{~nm}$ thickness is placed on the Pt wall. The upper boundary in the z-direction is an imaginary adiabatic elastic wall. The remaining volume is occupied by argon vapor. Both liquid and vapor are initially at their respective saturation states at $90 \mathrm{~K}$. The simulation domain initially comprises of 2645 liquid film argon atoms, 112 argon vapor atoms and 2929 Pt atoms. The time step is $5 \mathrm{fs}$. The Pt wall temperature is step-jumped from $90 \mathrm{~K}$ to $130 \mathrm{~K}$ at $\mathrm{t}=2000 \mathrm{ps}$.

The snapshots of $\mathrm{Y}-\mathrm{Z}$ plane of the computational domain are shown at different time steps in Fig. 10. The Pt wall atoms are denoted by the triangular symbols in red, the argon atoms forming the liquid film are shown in dark grey and the argon atoms in the vapor phase in light grey. After gradual vaporization of the initial liquid film, a nonevaporating liquid film forms towards the end of the simulation. This is confirmed by the facts that a) the number of liquid atoms constituting the film remains constant after a period of time, and b) the average temperature of the non-evaporating film is higher than the average vapor temperature. A thin film can exist in equilibrium on a solid surface even when its vapor pressure in the surrounding gas is below the normal saturation pressure for the system temperature (Carey, 1992).

The Hamaker constant, usually obtained experimentally between different materials using an atomic force microscope (Butt et al., 2005), was evaluated using molecular dynamics simulation for the nonevaporating film (Maroo and Chung, 2008). The Hamaker constant is a very helpful parameter and can be used to calculate the van der Waals force of interaction, dispersion energy, adhesive pressure, etc. It can also determine the magnitude of spreading of a film on different surfaces (Israelachvilli, 1994). A larger value of the Hamaker constant will result in a wetting film, whereas a comparatively smaller value leads to a non-wetting film. Starting from the Lennard-Jones potential, the energy of interaction between the non-evaporating Ar film and the Pt wall was derived: 


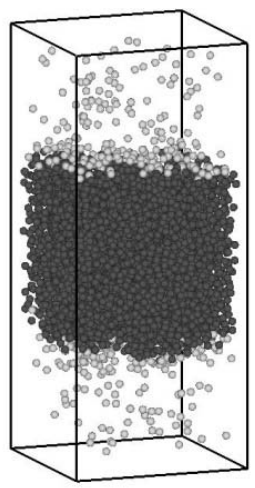

(a)

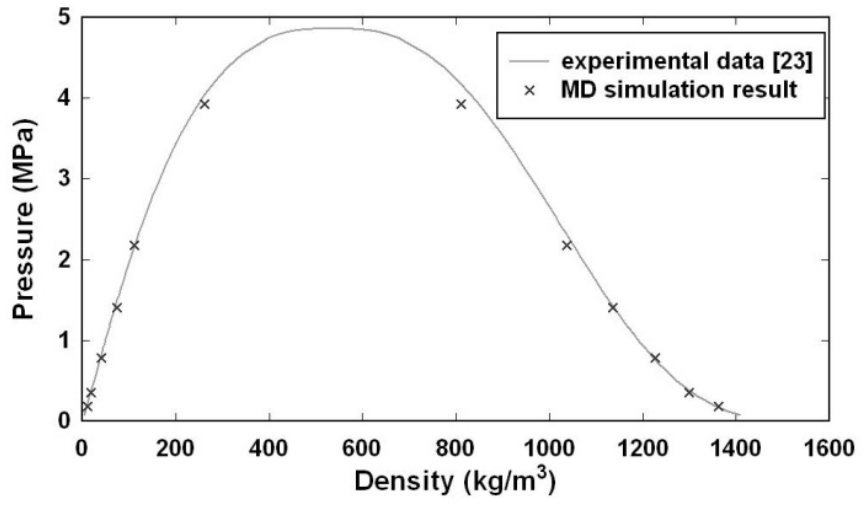

(b)

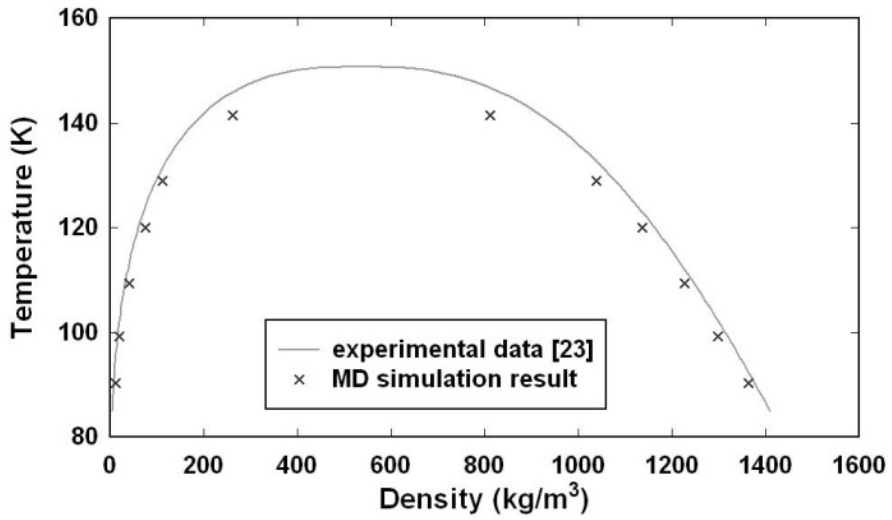

(c)

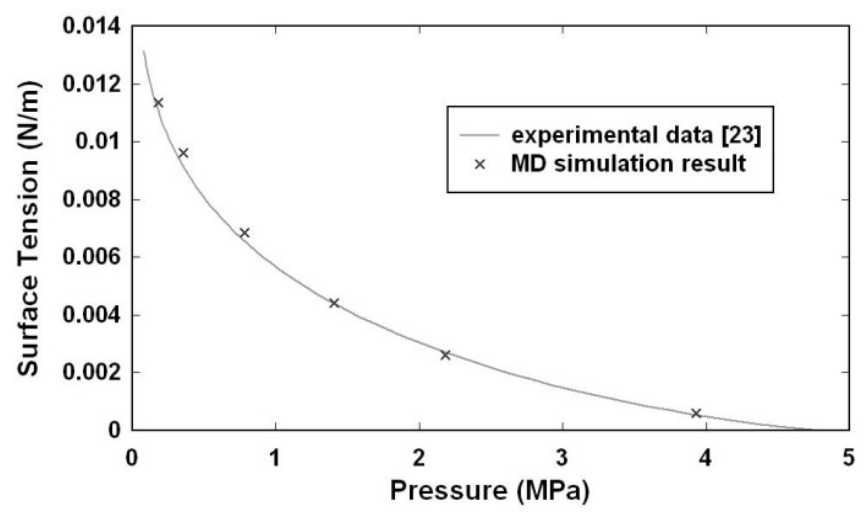

(d)

Fig. 9 Pressure verification with a liquid slab surrounded by vapor atoms, (a) 3-D snapshot of simulation domain, (b) Pressuredensity plot, (c) Temperature-density plot, (d) Surface tensionpressure plot (Maroo and Chung, 2009).

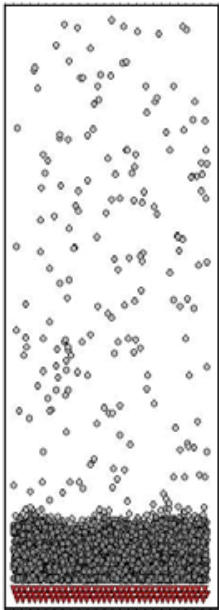

(a) $\mathrm{t}=2000 \mathrm{ps}$

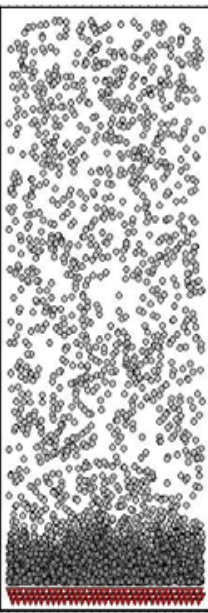

(b) t $=2800 \mathrm{ps}$

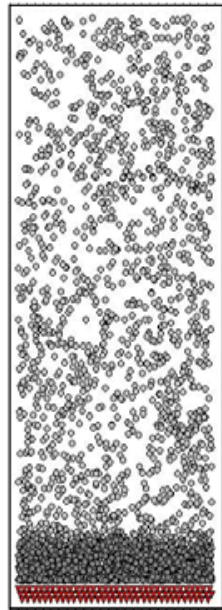

(c) $\mathrm{t}=4000 \mathrm{ps}$

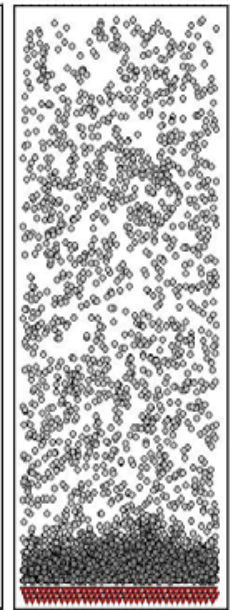

(d) $\mathrm{t}=6000 \mathrm{ps}$
Fig. 10 Evaporation sequence of liquid film of argon on Pt wall in the Y-Z plane along the computational domain. The liquid film does not completely evaporate and a non-evaporating film is obtained (Maroo and Chung, 2008).

$U_{L J}(d)=-\frac{A}{12 \pi}\left[\frac{1}{d^{2}}-\frac{1}{(t+d)^{2}}-\frac{\sigma^{6}}{30 d^{8}}+\frac{\sigma^{6}}{30(t+d)^{8}}\right]$

where, $A$ is a Hamaker-constant parameter defined as $A=4 \varepsilon\left(\frac{\rho N_{a v}}{M}\right)_{A r}\left(\frac{\rho N_{a v}}{M}\right)_{P t} \sigma^{6} \pi^{2}$, $\mathrm{d}$ is the gap between Ar and Pt slabs, $t$ is the thickness of the Ar slab and $U_{L J}$ is the total interaction energy between Ar-Pt slabs from molecular dynamics using LJ potential. The average value of $A$ was obtained as $5.28 \times 10^{-20} \mathrm{~J}$ with a standard deviation of $7.68 \%$.

In the previous simulation, the mirror boundary condition for the upper wall can introduce artifacts in the system. Thus, in order to remove such effects, thin film evaporation was simulated in an axisymmetric domain (Maroo and Chung, 2009). The simulation domain is now a nanochannel in the form of a cuboid as shown in Fig. 11. The $\mathrm{x}$ and $\mathrm{y}$ dimensions are $6.117 \mathrm{~nm} \times 6.117 \mathrm{~nm}$ respectively; $\mathrm{z}$ direction represents the channel height. A thin liquid argon film of thickness $t_{\text {film }}$ is placed on each Pt wall. The remaining volume is occupied by argon vapor. Both liquid and vapor are initially at their respective saturation states at $90 \mathrm{~K}$, and then the temperature of both walls is step-jumped to $130 \mathrm{~K}$ to simulate evaporation. Nanochannel height $h$ and initial film thickness $t_{\text {film }}$ are varied for different cases. Non-evaporating film in obtained in all cases. The pressure-density plots of particular interest in these simulations.

The average initial and final vapor pressures and vapor densities were evaluated for the simulation runs. Vapor pressure vs. vapor density for initial and final state is plotted for varying nanochannel height $h$ in Fig. 12(a), and for varying film thickness $t_{\text {flim }}$ in Fig. 12(b). The plots show that the states lie on the saturation curve, which is obtained from thermodynamics table of argon, implying that the vapor is saturated. This further validates the existence of the non-evaporating thin film; even though the film is superheated compared to the vapor temperature, no additional evaporation from the film can occur since the final vapor state is saturated.

\subsubsection{Interline region}

A concave meniscus was formed by placing liquid argon between a lower Pt wall and an upper Pt wall, with an opening in the upper wall as shown in Figs. 13a and 13b. The space above the meniscus is 


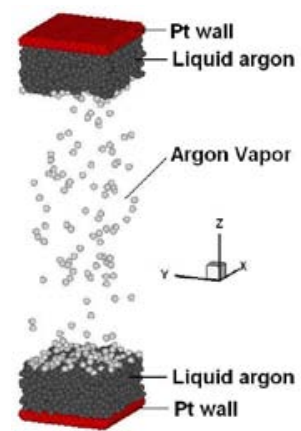

(a)

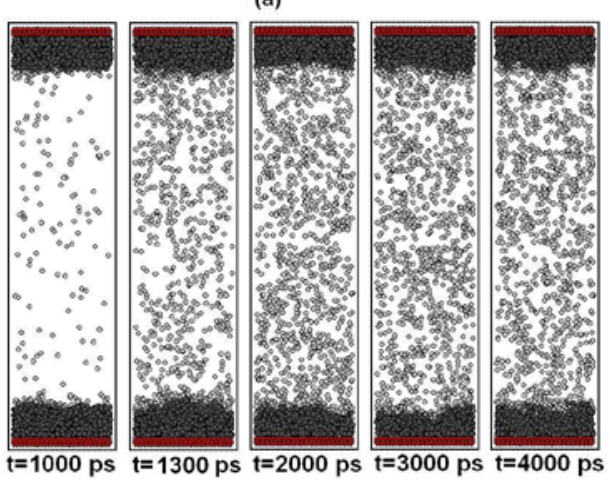

(b)

Fig. 11 Evaporation of thin liquid argon films in a nanochannel, (a) 3$\mathrm{D}$ view of nanochannel, (b) Snapshots of $\mathrm{x}$-z plane at different time intervals. Non-evaporating films form on both Pt walls. (Maroo and Chung, 2009).

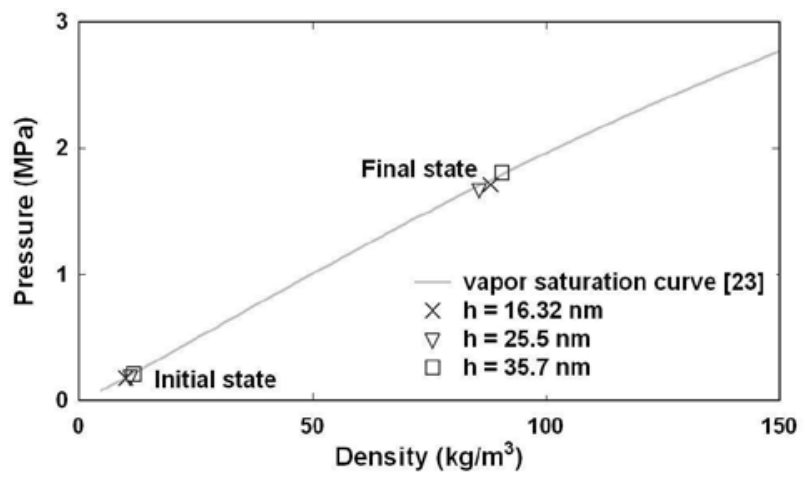

(a)

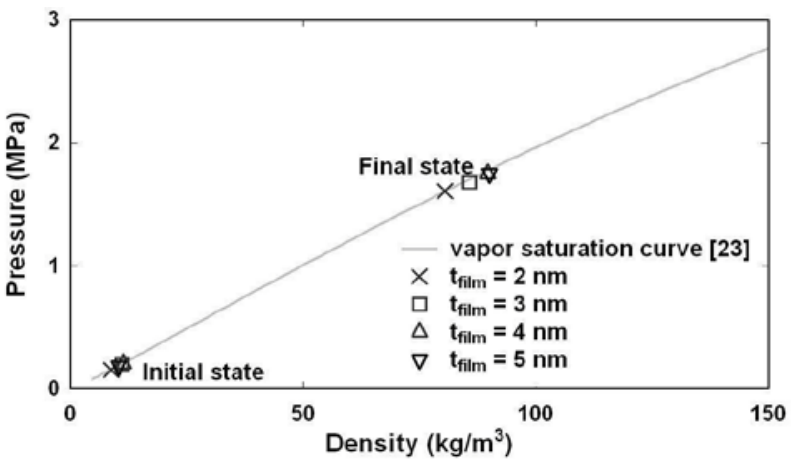

(b)

Fig. 12 (a) Vapor pressure-density plot of initial and final states for varying nanochannel height, (b) Vapor pressure-density plot of initial and final states for varying film thickness. Initial and final vapor states lie on the saturation curve. (Maroo and Chung, 2009).

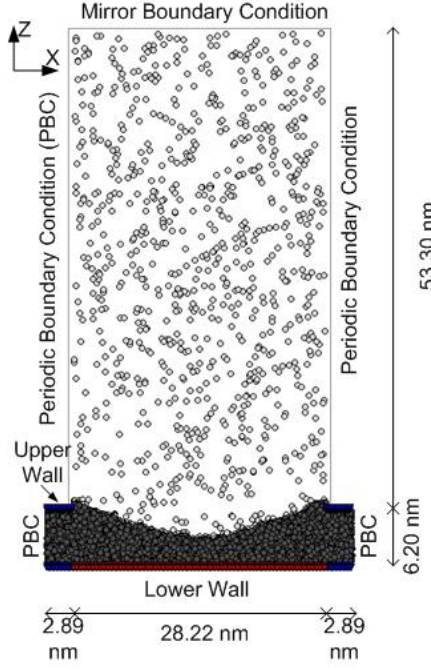

(a)

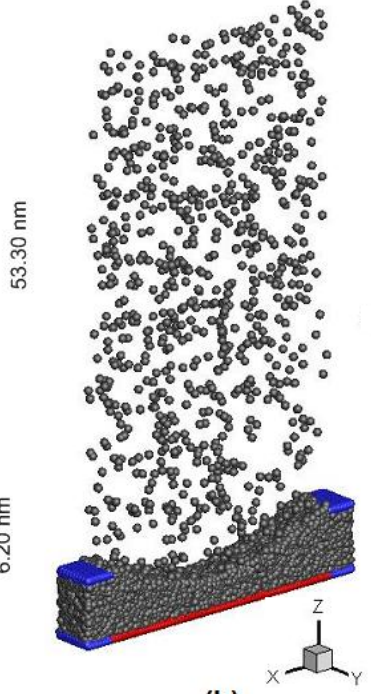

(b)
Fig. 13 Liquid argon meniscus, surrounded by argon vapor, in an opening constructed of platinum wall atoms. (a) 2D view along the $x-z$ plane depicting the boundary conditions and dimensions, and (b) 3D view of the simulation domain where the liquid-vapor interface can be clearly noticeable. Heat is transferred to the meniscus from the platinum wall region shown in red, while the region shown in blue is maintained at the lower initial temperature. (Maroo and Chung, 2010b).

occupied by argon vapor. The domain consists of a total of 14172 argon atoms and 7776 platinum atoms. The total width, height and depth are $34 \mathrm{~nm}, 59.5 \mathrm{~nm}$ and $4.3 \mathrm{~nm}$ respectively. The width of the opening in the upper wall is $28.22 \mathrm{~nm}$. The separation between the lower wall and the upper wall is $6.2 \mathrm{~nm}$. The initial equilibrium temperature is $90 \mathrm{~K}$. The time step is 5 fs. All the boundaries in $\mathrm{x}$ and $\mathrm{y}$ directions are periodic. The length of the boundary above the upper wall in the $\mathrm{x}$ direction is restricted to the width of the opening. Any argon atom which goes above the upper wall does not interact with the wall atoms anymore. The top boundary in the z-direction is the mirror boundary condition. The temperature of part of the lower wall, which is directly underneath the opening (shown in red in Fig. 13a and 13b), is increased to $130 \mathrm{~K}$, while the upper wall and the remainder of lower wall (shown in blue color) are kept at their initial value of $90 \mathrm{~K}$ during the heating period.

With continuous evaporation taking place, the thinnest part of the meniscus at the center continues to decrease in thickness (Fig. 14) until a uniform non-evaporating film forms. It is also shown that evaporation still occurs in the adjacent regions to the non-evaporating film, which are hence the interline region. Heat and evaporation fluxes are evaluated, and it is shown that ultra-high heat flux on the order of 100 $\mathrm{MW} / \mathrm{m}^{2}$ and high evaporation rates on the order of $1000 \mathrm{~kg} / \mathrm{m}^{2} \mathrm{~s}$ are achievable from the nano-region of the three-phase contact line (Fig. 15).

\subsubsection{Negative Liquid Pressure}

Capillary forces are of main importance in micro- and macro- scale fluidic systems. However at nanoscale, disjoining forces can become extremely dominant. These disjoining forces can cause liquid films to be under high absolute negative pressures. A better insight into negative liquid pressures can be gained from the phase diagram of water, which shows the stable, metastable and unstable regions (Angell, 1988).

It has been shown that predictions of equilibrium vapor pressure from the conventional disjoining pressure theory agree well with molecular dynamics simulation predictions, even for extremely thin film thicknesses where no bulk liquid region separates the wall-affected region from the interfacial region (Carey and Wemhoff, 2006). The 
pressure in the liquid film is obtained using the augmented YoungLaplace equation: $P_{L}=P_{v}-P_{c}-P_{d}$, where $P_{L}$ is the liquid pressure, $P_{v}$ is the vapor pressure, $P_{c}$ is the capillary pressure and $P_{d}$ is the disjoining pressure. Due to high disjoining pressure values in the non-evaporation film region, and partially due to capillary forces in its adjacent regions, the liquid is found to be under deep negative pressure at the center of the meniscus. Usually, at macroscale, liquid regions subject to negative pressures cavitate and form bubbles. However, for the formation of a spherical vapor bubble, a critical radius of cavitation $R_{c}$ (defined as: $R_{c}=-2 \gamma_{L V} / P_{\text {liquid }}$ ) has to be achieved (Fisher, 1948). Thus, cavitation can be avoided if the critical cavitation radius is larger than the smallest characteristic dimension (Zhang et al., 2010). To verify this aspect in our work, a normalized function $\log \left(\Pi / \delta_{n e}\right)$ is plotted in the region of negative liquid pressure for $\Pi=R_{C}=-2 \gamma / P_{L}$ and $\Pi=\delta(x)$, as shown in Fig. 16, where $\delta_{n e}$ is the thickness of the attained nonevaporating film. The normalized function has higher values for $\Pi=R_{C}$ compared to $\Pi=\delta(x)$, which signifies that the critical cavitation radius is larger than the meniscus height. Thus, the liquid meniscus region under high negative pressures can exist in metastable state.

We believe these molecular dynamics simulations provide valuable insight towards further understanding the physics that might be occurring at the contact line at the base of a bubble. We speculate that a stable negative liquid pressure exists in the non-evaporating film region which assists in the liquid flow from the intrinsic meniscus to the evaporating film region during bubble nucleation and growth.

\section{FUTURE RESEARCH NEEDS}

During the past two decades, nano/micro technologies have made unprecedented progress that has enabled the availability of more advanced diagnostic tools and more powerful computers. As a result, researchers will be able to explore deeper into the fundamental science of boiling in the future. We suggest the following for future research consideration:

1. Unlock the basic transport physics of the MCL associated with a bubble during its growth, coalescence and departure in nucleate boiling. Further more, determine the role of the MCL during the bubble-bubble coalescence and its effects on fluid mechanics and heat transfer in the micro- and macro-layers and then to develop a mechanistic model for this phenomenon.

2. Obtain a fundamental understanding on the physics of $\mathrm{CHF}$ and the relationship of single bubble dynamics and bubble-bubble coalescence to the transport mechanisms associated with the CHF phenomenon of Nucleate boiling.

3. Develop mechanistic models with no adjustable constants for nucleate boiling and critical heat flux.

More specifically, we suggest the delineation through simulation and analysis of the contributions of the key mechanisms to the total boiling heat transfer. This includes the MCL with micro/macro layer evaporation on single and merged bubbles attached to a heated wall, and heat transfer enhancement during coalescence of bubbles on the heater wall. It would be enlightening to provide answers to the following:

1. What mechanisms are at play during bubble growth and coalescence? In other words, how do the thermodynamic force, surface tension force, and hydrodynamic force that are associated with the MCL process balance one another?

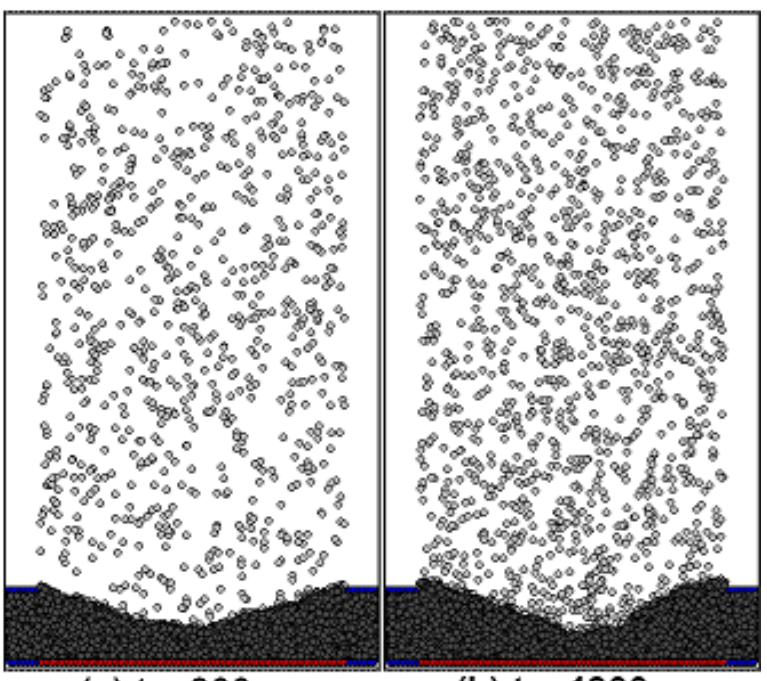

(a) $\mathrm{t}=900 \mathrm{ps}$

(b) $\mathrm{t}=1300 \mathrm{ps}$

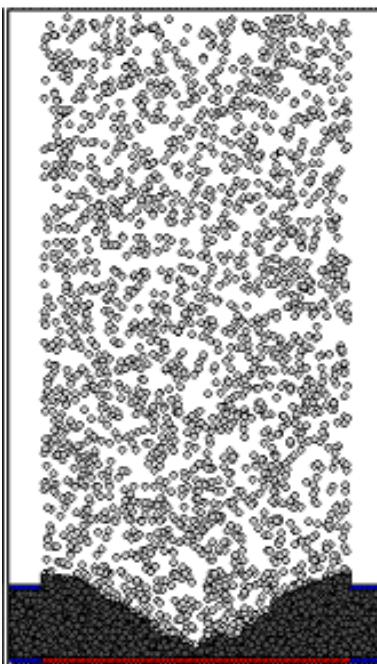

(c) $\mathrm{t}=1700 \mathrm{ps}$

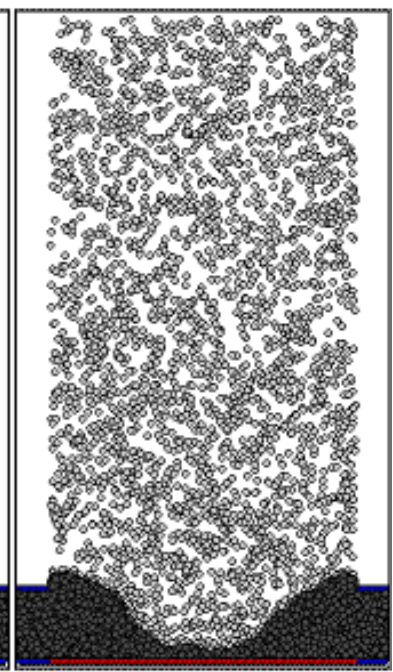

(d) $\mathrm{t}=2500 \mathrm{ps}$
Fig. 14 Snapshots of $x-z$ plane at different time steps of evaporating nanoscale meniscus. Non-evaporating film is obtained at the center of the meniscus, while the interline region is present in the adjacent regions. (Maroo and Chung, 2010b).

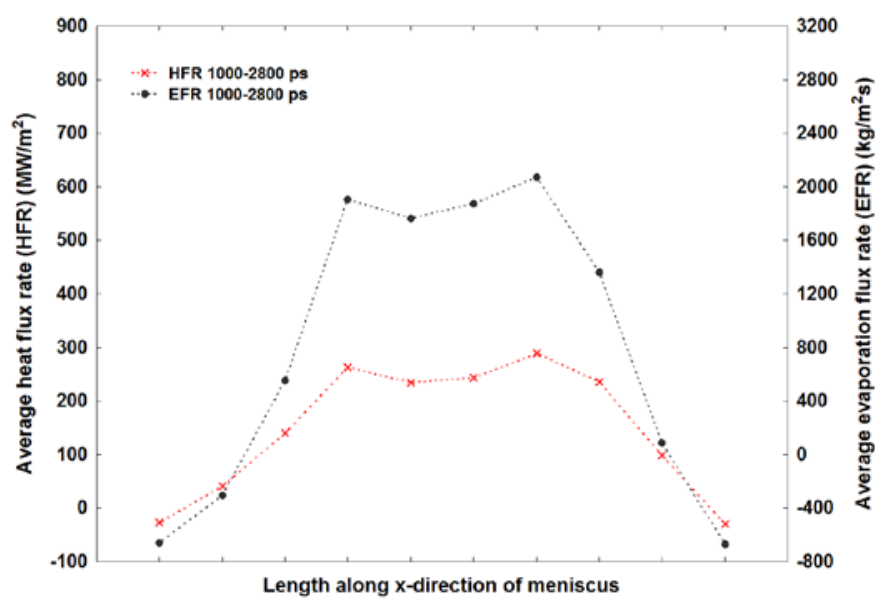

Fig. 15 Average heat and evaporation flux values along the length of the nanoscale meniscus. (Maroo and Chung, 2010b). 


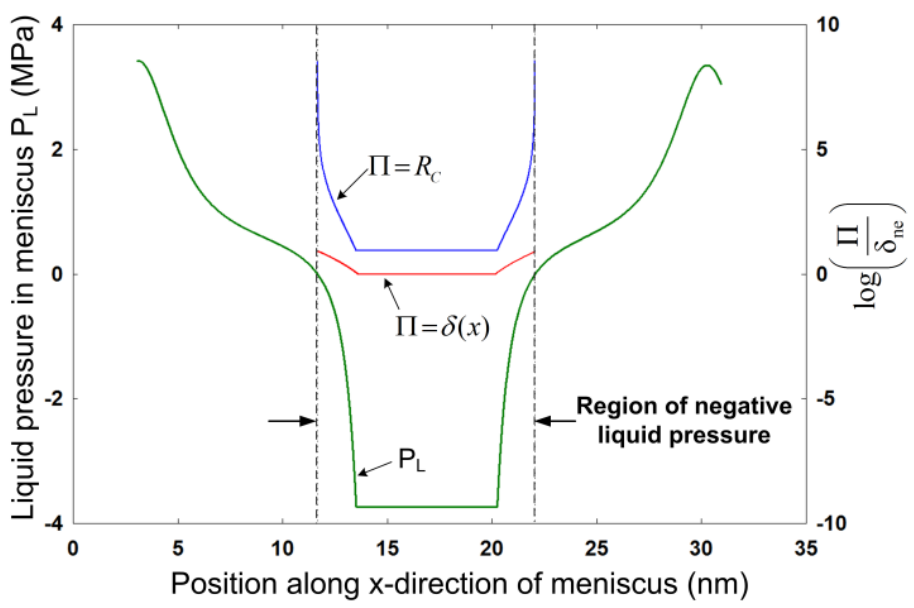

Fig. 16 Variation in liquid pressure along the meniscus at $t=2500$ ps for the nanoscale meniscus. High negative pressure values are seen at the center of the meniscus. A normalized function $\log \left(\Pi / \delta_{n e}\right)$ is plotted in the region of negative liquid pressure for $\Pi=R_{C}=-2 \gamma / P_{L}$ and $\Pi=\delta(x)$, which nullifies the possibility of cavitation in this region as the meniscus thickness is smaller than the critical cavitation radius. (Maroo and Chung, 2011).

2. What controls the bubble growth dynamics and departure from the heater surface in nucleate boiling when bubble coalescence is part of the process?

3. What are the controlling parameters for vaporization and heat transfer around the MCL ?

4. How does the heater surface superheating level affect the MCL bubble dynamics?

5. What are the effects due to different system parameters such as the system pressure and surface characteristics on the bubble growth and coalescence dynamics?

6. What is the relationship of bubble growth and coalescence with the critical heat flux?

7. For nanofluids, what the fundamental heat transfer enhancement physics for a wide range of nano-particle materials and applicable coolants?

\section{CONCLUSION}

In this review paper, based on nano/micro scale experimental and theoretical/numerical results reported in the open literature we have presented an up-to-date summary on the recent advances of fundamental nucleate boiling physics. For the heterogeneous nucleate boiling, the interaction between the bubble and the heat source (heater surface) is facilitated through a multiscale (nano, micro and macro regions) liquid layer that couples the bubble with the heater surface. The moving contact line (MCL) is the nanoscale and most inner region where the vapor-liquid-solid phases meet and this liquid layer is at its thinnest. The dynamics, and the heat and mass transfer characteristics around the MCL hold the key for bubble growth, detachment and departure. In the micro-heater experiment, bubble detachment and departure, and bubble-bubble coalescence have been found to induce heat flux spikes that boost the heat transfer rates. There is also evidence that bubble coalescence could be the main mechanism responsible for the high heat flux nucleate boiling and also is connected to the critical heat flux.

In general, for miniature heaters the critical heat flux increases as the heater size decreases. The effect of heater size on boiling performance prior to the critical heat flux was found that boiling heat transfer is inversely proportional to heater size. Further more, boiling on microheaters is characterized by larger bubble departure sizes, smaller bubble growth rates due to the dryout of microlayer as the bubble grows, and higher bubble incipience superheat. As the heater size decreases, the boiling curve moves towards higher heat fluxes with corresponding higher superheats. The unique heat transfer processes associated with boiling on a microheater are considerably different from those typically observed during boiling on a macroscale heater. In many MEMS applications, small heaters are designed for super-high rates of heating in a confined space environment that usually results in explosive homogeneous nucleation such as those in bubble-actuated Microsystems.

Addition of nanoscale solid particles in liquids such as water has been shown to substantially expand the cooling thresholds for phasechange heat transfer. In general, nanofluids have been shown to drastically increase the critical heat fluxes while their effects on the nucleate boiling regime is not very significant. Some even reported that the nanofluids lowered the boiling heat transfer. For one theory, the effect of nanoparticles on boiling heat transfer is thought to be due to a change in wetting characteristics by the nanofluids and the formation of a porous layer on the heating surface. Another theory predicted that the improved heat transfer is due to an increase in thermal conductivity that results from an increased motion of liquid atoms in the presence of nanoparticles. However, many controversies still exist concerning the application of nano-fluids, fundamental research efforts are needed.

Heater surfaces manufactured with nanoscale textures have also been the subject of recent research activities. These nano-surface textures, mainly carbon nano tubes, have the potential to alter the surface properties such as wettability and thermal conductivity. Also they might provide more favorable nucleation sites for boiling and condensation initiations. Nano-surface textures have been shown to improve nucleate boiling mainly for lower heat fluxes as they enhance nucleation but do not promote bubble departure.

Numerical techniques have been developed in the recent decades to simulate the three phase contact line region of a bubble. Due to the multi-scale nature of the contact line, continuum numerical simulations have been used to study for the evaporating and intrinsic meniscus region which are on the length scale of micrometers and higher. It has been found by researchers that majority of the heat transfer to the growing bubble occurs in the evaporating thin film region. Molecular dynamics simulations have been recently performed by Maroo and Chung (2008, 2009, 2010a, 2010b, 2011) to gain insight into the nonevaporating and interline region. These regions are nanometer sized films and thus may not be modeled using continuum mechanics. The formation of the non-evaporating film was simulated, and the Hamaker constant of the film was evaluated. The interline region along with the non-evaporating region was obtained from an evaporating curved meniscus. Ultra-high heat fluxes, on the order of $100 \mathrm{MW} / \mathrm{m}^{2}$ and higher, occur in the interline region. It was also shown that the nonevaporating film can be under high absolute negative pressure due to the effect of disjoining pressure. This pressure difference in the nonevaporating region and the intrinsic meniscus causes liquid to flow towards the evaporating region, and allows continuous evaporation and growth of bubble. Thus, in order to accurately predict bubble nucleation and growth, future research should be directed towards multi-scale simulation of the three-phase contact line where molecular dynamics and continuum simulations can be performed in coherence in the same computational domain. Multi-scale simulations will allow us to further elucidate the dimensional and heat transfer characteristics of the interline region. 


\section{ACKNOWLEDGMENTS}

The support by the Andrew H. Hines, Jr./Progress Energy Endowment Fund is acknowledged.

\section{REFERENCES}

Ahn, H.S., Sathyamurthi, V., and Banerjee, D., 2009, "Pool Boiling Experiments on a Nano-Structured Surface", IEEE Transaction on Components and Packaging Technologies, 32, 156-165. doi:10.1109/TCAPT.2009.2013980

Angell, C.A., 1988, "Approaching the limits," Nature, 331(6153), 206207.

doi: $10.1038 / 331206 \mathrm{a} 0$

Avedisian, C.T., Osborne, W.S., McLeod, F.D., and Curley, C.M. 1999, "Measuring Bubble Nucleation Temperature on the Surface of a Rapidly Heated Thermal Inkjet Heater Immersed in a Pool of Water," Proc. R. Soc. Lond. A, 455, 3875-3899.

doi: 10.1098/rspa.1999.0481

Baker, E., 1973, "Liquid Immersion Cooling of Small Electronic Devices,” Microelectron. Relib., 12, 163-173.

Balss, K.M., Avedisian, C.T., Cavicchi, R.E., Tarlov, M.J., 2005, "Nanosecond Imaging of Microboiling Behavior on Pulsed-Heated Au Films Modified with Hydrophilic and Hydrophobic Self-Assembled Monolayers," Langmuir, 21, 10459-10467.

doi: $10.1021 / \mathrm{la} 040137 \mathrm{t}$

Blake, T.D, 2006, “The physics of moving wetting lines,” J. Colloid and Interface Science, 299, 1-12.

doi:10.1016/j.jcis.2006.03.051

Bonjour, J.M., Clausse, M., Lallemand, M., 2000, “Experimental Study of the Coalescence Phenomenon during Nucleate Pool Boiling," Exp. Thermal Fluid Sci., 20, 180-187. doi:10.1016/S0894-1777(99)00044-8

Buongiorno, J., 2006, “Convective Transport in Nanofluids,” Journal of Heat Transfer, 128, 240-251.

doi: $10.1115 / 1.2150834$

Buongiorno, J., Lin-Wen Hu, Sung Joong Kim, Ryan Hannink, Bao Truong and Eric Forrest, 2008, "Nanofluids for Enhanced Economics and Safety of Nuclear Reactors: An Evaluation of the Potential Features, Issues, and Research Gaps,” Nuclear Technology, 162 (1), 8091.

Butt, H., Cappella, B. and Kappl, M., 2005, "Force measurements with the atomic force microscope: Technique, interpretation and applications," Surface Science Reports, 59(1-6), 1-152.

doi:10.1016/j.surfrep.2005.08.003

Carey, V.P., 1992, Liquid-vapor phase-change phenomena, Taylor and Francis, 672pp.

Carey, V.P. and Wemhoff, A.P., 2006, "Disjoining pressure effects in ultra-thin liquid films in micropassages - Comparison of thermodynamic theory with predictions of molecular dynamics simulations," Journal of Heat Transfer-Transactions of the ASME, 128(12), 1276-1284.

doi:10.1115/1.2349504
Chang, J.Y. and You, S.M., 1996, "Heater Orientation Effects on Pool Boiling of Micro-Porous-Enhanced Surfaces in Saturated FC-72,” $J$. Heat Transfer, 118, 937-943.

doi:10.1115/1.2822592

Chen, L., Wang, Z., Wang, P.I., Peles, Y., Koratkar, N., and Peterson, G.P., 2008, "Nanostructured Copper Interfaces for Enhanced Boiling," Small, 4(8), 1084-1088. doi: $\underline{10.1002 / \mathrm{smll} .200700991}$

Chen, R., Lu, M., Sninivasan, V., Wang, Z., Cho, H.H., and Majumdar, A., 2009, "Nanowires for Enhanced Boiling Heat Transfer," Nano Letters, 9(2), 549-553.

doi: $\underline{10.1021 / \mathrm{nl} 8026857}$

Chen, T. and Chung, J.N., 2002, "Coalescence of Bubbles in Nucleate Boiling on Microheaters," International Journal of Heat and Mass Transfer, 45, 2329-2341. doi:10.1016/S0017-9310(01)00334-9

Chen, T. and Chung, J.N., 2003a, "Experimental Study of MiniatureScale Pool Boiling,” ASME Journal of Heat Transfer, 125, 1074-1086. doi:10.1115/1.1603773

Chen, T. and Chung, J.N., 2003b, "Heat Transfer Effects of Coalescence of Bubbles from Various Site Distributions," Proceedings of Royal Society, England: Mathematical, Physical and Engineering Sciences, 459, 2497-2527.

doi:10.1098/rspa.2003.1133

Chen, T., Klausner, J.F., and Chung, J.N., 2004, "Subcooled boiling heat transfer and dryout on a constant temperature microheater," Int. J. Heat Fluid Flow, 25, 274-287.

doi:10.1016/j.ijheatfluidflow.2003.11.014

Chen, T., Klausner, J.F., Garimella, S.V., and Chung, J.N., 2006, "Subcooled Boiling Incipience on a Highly Smooth Microheater," International Journal of Heat and Mass Transfer, 49, 4399-4406. doi:10.1016/j.ijheatmasstransfer.2006.05.008

Choi, S.U.S., 1995, "Enhancing Thermal Conductivity of Fluids with Nanoparticles," In: Siginer, D.A. and Wang, H.P. eds. Developments and Applications of Non-Newtonian Flows, ASME, New York, FED Vol. 231/MD - Vol. 66, 99-105.

Choi, S.U.S., Zhang, Z.G., Yu, W., Lockwood, F.E., and Grulke, E.A., 2001, "Anomalous Thermal Conductivity Enhancement in Nanotube Suspension,” Appl. Phys. Lett., 79(14), 2252-2254. doi:10.1063/1.1408272

Cooper, M.G. and Lloyd, A. J. P., 1969, "The Microlayer in Nucleate Boiling,” International Journal of Heat and Mass Transfer, 12, 895913.

doi:10.1016/0017-9310(69)90154-9

Das, S.K., Narayan, G.P., and Baby, A.K., 2008, "Survey on Nucleate Pool Boiling of Nanofluids: the Effect of Particle Size relative to Roughness,” Journal of Nanoparticle Research, 10(7), 1099-1108. doi: 10.1007/s11051-007-9348-x

Das, S.K., Putra, N., and Roetzel, W., 2003, "Pool Boiling Characteristics of Nano-Fluids," International Journal of Heat Mass Transfer, 46, 851-862.

doi:10.1016/S0017-9310(02)00348-4 
Demiray, F. and Kim, J., 2004, "Microscale Heat Transfer Measurements during Pool Boiling of FC-72: Effect Of Subcooling," International Journal of Heat Mass Transfer, 47, 3257-3268. doi:10.1016/j.ijheatmasstransfer.2004.02.008

Dhir , V.K., and Liaw, S.P., 1989, "Framework for a unified model for nucleate and transition pool boiling," ASME J. Heat Transfer, 111, 739-746.

doi:10.1115/1.3250745

Dhir, F.K., 1990, "Nucleate and Transition Boiling Heat Transfer Under Pool and External Flow Boiling," Proc. $9^{\text {th }}$ Int Heat Conference, 1, 129-155.

Dhir, V.K., 2006, "Mechanistic prediction of nucleate boiling heat transfer - Achievable or a hopeless task?" Journal of Heat TransferTransactions of the ASME, 128(1), 1-12.

doi:10.1115/1.2136366

Ding, H. and Spelt, P.D.M., 2007a, "Inertia effects in droplet spreading: a comparison between diffuse-interface and level-set simulations," $J$. Fluid Mech., 576, 287-206. doi: $10.1017 / \mathrm{S} 0022112007004910$

Ding, H., and Spelt, P. D.M., 2007b, "Wetting condition in diffuse interface simulations of contact line motion,” Phys. Rev. E, 75, 046708. doi:10.1103/PhysRevE.71.041602

Dussan, V., E. B. and Davis, S. H., 1974, "On the motion of a fluidfluid interface along a solid surface,” J. Fluid Mech., 65, 71. doi: $10.1017 /$ S0022112074001261

Dussan, V., E. B., 1976, “The moving contact line: the slip boundary condition,” J. Fluid Mech., 77, 665

doi: $\underline{10.1017 / \mathrm{s} 0022112076002838}$

Dussan, V., E. B., 1979, “On the spreading of liquids in solid surfaces: static and dynamic contact lines,” Ann. Rev. Fluid Mech., 11, 371. doi: 10.1146/annurev.fl.11.010179.002103

Eastman, J.A., Choi, S.U.S., Li, S., Yu, W., and Thompson, L.J., 2001, "Anomalously Increased Effective Thermal Conductivity of Ethylene Glycol-Based Nanofluids Containing Copper Nanoparticles,” Appl. Phys. Lett., 78(6), 718-720.

doi: $10.1063 / 1.1341218$

Fisher, J.C., 1948, "The Fracture of Liquids," Journal of Applied Physics, 19(11), 1062-1067.

doi: $10.1063 / 1.1698012$

Forster, H. K. and Grief, R., 1959, "Heat Transfer to a Boiling LiquidMechanisms and Correlations,” Journal of Heat Transfer, 81, 45-59.

Forster, H. K. and Zuber, N., "Dynamics of Vapor Bubbles and Boiling Heat Transfer,” AICHE Journal, 1, 531-542.

doi: 10.1002/aic.690010425

Fuentes, J., and Cerro, R.L., 2007, "Surface forces and inertial effects on moving contact lines," Chemical Engineering Science, 62(12), 32313241.

doi:10.1016/j.ces.2007.03.012

Gad-el-Hak, M., 1999, "The Fluid Mechanics of Microdevices-The Freeman Scholar Lecture,” Journal of Fluids Engineering, 121, 5-31. doi: $10.1115 / 1.2822013$
Genske, P. and Stephan, K., 2006, "Numerical simulation of heat transfer during growth of single vapor bubbles in nucleate boiling," International Journal of Thermal Sciences, 45(3), 299-309.

doi:10.1016/j.ijthermalsci.2004.07.008

Gogonin, I.I. and Kutaleladze, S.S., 1977, "Critical Heat Flux as a Function of Heater Size for a Liquid Boiling in a Larger Enclosure,” $J$. Engrg. Phys., 33, 1286-1289.

doi: 10.1007/BF00860899

Granovskii, V.S., Sulatskii, A.A., and Shmelev, S.M., 1994, "The Crisis of Nucleate Boiling on a Horizontal Surface Facing Downward,” High Temp., 32, 78-80.

Haddad, K.H. and Cheung, F.B., 1998, "Steady-State Subcooled Nucleate Boiling on a Downward-Facing Hemispherical Surface," Journal of Heat Transfer (ASME), 120, 365-370.

doi:10.1115/1.2824258

Han, C. Y. and Griffith, P., 1965, "The Mechanism of Heat Transfer in Nucleate Pool Boiling," International Journal of Heat and Mass Transfer, 8, 887-914. doi:10.1016/0017-9310(65)90073-6

Haramura , Y., and Katto, Y., 1983, “A new hydrodynamic model of critical heat flux applicable widely to both pool and forced convection boiling on submerged bodies in saturated liquids," Int. J. Heat Mass Transfer, 26, 389-399. doi:10.1016/0017-9310(83)90043-1

Hazi, G. and Markus, A., 2009, "On the bubble departure diameter and release frequency based on numerical simulation results," International Journal of Heat and Mass Transfer, 52(5-6), 1472-1480.

doi:10.1016/j.ijheatmasstransfer.2008.09.003

Hendricks, R.C. and Sharp, R.R. 1964, "Initiation of Cooling due to Bubble Growth on a Heating Surface,” NASA TND2290.

Hijikata, K., Yamamoto, N., and Takagi, S., 1997, "Boiling Heat Transfer from a Micro Heater,'” Micro-Electronics-Mechanical Systems (MEMS), ASME, New York.

Hsieh, S.S. and Lin, C.Y., 2010, "Subcooled Convective Boiling in Structured Surface Microchannels," Journal of Micromechanics and Microengineering, 20, 015027. doi: 10.1088/0960-1317/20/1/015027

Huh, C. and Scriven, L. E., 1971, "Hydrodynamics model of steady movement of a solid/liquid/fluid contact line,” J. Colloid Interface Sci., 35, 85. doi:10.1016/0021-9797(71)90188-3

Iida, Y., Okuyama, K., and Sakurai, K., 1994, "Boiling Nucleation on a Very Small Film Heater Subjected to Extremely Rapid Heating,” Int. J. Heat Mass Transfer, 37, 2771-2780. doi:10.1016/0017-9310(94)90394-8

Ishigai, S., Inoue, K., Kiwaki, Z., and Inai, T., 1961, "Boiling Heat Transfer from a Flat Surface Facing Downward," Proceedings of the International Heat Transfer Conference, Boulder, CO., 224-229.

Israelachvilli, J., 1994, Intermolecular \& Surface Forces, $2^{\text {nd }}$ ed., Academic Press

Jo, B., Jeon, P.S., Yoo, J., and Kim, H.J., 2009, "Wide Range Parametric Study for the Pool Boiling of Nano-fluids with a Circular Plate Heater,” Journal of Visualization, 12(1), 37-46. 
Kandlikar, S.G., 2006, "Effect of liquid-vapor phase distribution on the heat transfer mechanisms during flow boiling in minichannels and microchannels," Heat Transf. Eng., 27(1), 4-13.

doi: 10.1080/01457630500341607

Kandlikar, S.G., Shoji, M. and Dhir, V.J., 1999, Handbook of Phase Change: Boiling and Condensation, Taylor \& Francis.

Katto, Y., 1994, “Critical Heat Flux,” Int. J. Multiphase Flow, 20, 5390.

doi:10.1016/0301-9322(94)90070-1

Kim, S.J., Bang, I.C., Buongiorno, J., and Hu, L.W., 2007, "Study of Pool Boiling and Critical Heat Flux Enhancement in Nanofluids," Bulletin of the Polish Academy of Sciences Technical Sciences, 55(2), 211-216.

Koplik, J., Banavar, J. R., and Willemsen, J. F., 1988, "Molecular dynamics of Poiseuille flow and moving contact lines," Phys. Rev. Lett., 60(13), 1282-1285.

doi:10.1103/PhysRevLett.60.1282

Kwon, Y.M. and Chang, S.H., 1999, "A Mechanistic Critical Heat Flux Model for Wide Range of Subcooled and Low Quality Flow Boiling," Nucl. Eng. Des., 188, 27-47. doi:10.1016/S0029-5493(99)00025-4

Launay, S., Fedorov, A.G., Joshi, Y., Cao, A., and Ajayan, P.M., 2006, "Hybrid Micro-Nano Structured Thermal Interfaces for Pool Boiling Heat Transfer Enhancement,” Microelectronics Journal, 37(11), 11581164.

doi:10.1016/j.mejo.2005.07.016

Lee, R.C. and Nydahl, J.E., 1989, "Numerical Calculation of Bubble Growth in Nucleate Boiling From Inception Through Departure," Journal of Heat Transfer-Transactions of the ASME, 111(1-4), 474479.

doi: $10.1115 / 1.3250701$

Lee, S., Choi, S.U.S., Li, S., and Eastman, J.A., 1999, "Measuring Thermal Conductivity of Fluids Containing Oxide Nanoparticles," J. Heat Transfer, 121, 280-289.

doi:10.1115/1.2825978

Lee, W., Son, G. and Jeong, J.J., 2010, "Numerical Analysis of Bubble Growth and Departure from a Microcavity," Numerical Heat Transfer Part B-Fundamentals, 58(5), 323-342.

doi:10.1080/10407790.2010.522871

Liao, J., Mei, R. and Klausner, J.F., 2004, "The influence of the bulk liquid thermal boundary layer on saturated nucleate boiling," International Journal of Heat and Fluid Flow, 25(2), 196-208. doi:10.1016/j.ijheatfluidflow.2003.11.012

Lienhard, J.H., 1988a, "Burnout on Cylinders," Trans. ASME J. Heat Transfer, 113, 548. doi:10.1115/1.3250626

Lienhard, J.H., 1988b, “Things we don't know about boiling heat transfer,” Int. Commun. Heat Mass Transfer, 15, 401-428. doi:10.1016/0735-1933(88)90041-3

Lienhard, J.H., and Dhir, V.K., 1973, "Extended hydrodynamic theory of the peak and minimum pool boiling heat fluxes,” NASA CR-2270.

Lienhard, J.H., Dhir, V.K., and Riherd, D.M., 1973, "Peak Pool Boiling Heat Flux Measurements on Finite Horizontal Flat Plates," ASME J. Heat Transfer, 95, 477-482. doi:10.1115/1.3450092

Lin, L., Pisano, A.P., and Carey, V.P., 1998, "Thermal Bubble Formation on Polysilicon Micro Resistors," J. Heat Transfer, 120, 735742.

doi:10.1115/1.2824343

Liu, C.H. and Cheng, C.M., 2007, "An Electrolysis-Based BubbleActuated Micropump”, SPIE Newsroom, 10.1117/2.1200705.0716.

Ma, K.T. and Pan, C., 1999, "Thermo-capillary driven flow in macrolayer at high wall heat fluxes," International Journal of Numerical Methods for Heat \& Fluid Flow, 9(7), 788-808. doi: 10.1108/09615539910291163

Maroo, S.C. and Chung, J.N., 2008, "Molecular dynamic simulation of platinum heater and associated nano-scale liquid argon film evaporation and colloidal adsorption characteristics," Journal of colloid and interface science, 328(1), 134-146.

doi: $\underline{10.1016 / j . j c i s .2008 .09 .018}$

Maroo, S.C. and Chung, J.N., 2009, "Nanoscale liquid-vapor phasechange physics in nonevaporating region at the three-phase contact line," Journal of Applied Physics, 106(6), 064911.

doi:10.1063/1.3225992

Maroo, S.C. and Chung, J.N., 2010a, "A novel fluid-wall heat transfer model for molecular dynamics simulations," Journal of Nanoparticle Research, 12(5), 1913-1924.

doi:10.1007/s11051-009-9755-2

Maroo, S.C. and Chung, J.N., 2010b, "Heat transfer characteristics and pressure variation in a nanoscale evaporating meniscus," International Journal of Heat and Mass Transfer, 53(15-16), 3335-3345.

doi:10.1016/j.ijheatmasstransfer.2010.02.030

Maroo, S. and Chung, J.N., 2011, "Negative pressure characteristics of an evaporating meniscus at nanoscale," Nanoscale Research Letters, 6(1), 72.

doi:10.1186/1556-276X-6-72

Maruyama, S., and Kimura, T., 2000, "A molecular dynamics simulation of a bubble nucleation on solid surface," Int. J. Heat Tech., 18, 69-74.

Mikic, B. B., Rohsenow, W. M., and Griffith, P., 1969, "On Bubble Growth Rates,” International Journal of Heat and Mass Transfer, 13, 657-666.

doi: $10.1016 / 0017-9310(70) 90040-2$

Moffatt, H.K., 1964, "Viscous and resistive eddies near a sharp corner," J. Fluid Mech., 18, 1-18. doi:10.1017/S0022112064000015

Moore, F. D. and Mesler, R. B., 1961, "The Measurement of Rapid Surface Temperature Fluctuations during Nucleate Boiling of Water," AICHE Journal, 7, 620-624.

doi:10.1002/aic.690070418

Mukherjee, A. and Dhir, V.K., 2004, "Study of lateral merger of vapor during nucleate pool boiling," Journal of Heat Transfer-Transactions of the Asme, 126(6), 1023-1039.

doi:10.1115/1.1834614

Mukherjee, A. and Kandlikar, S.G., 2007, "Numerical study of single bubbles with dynamic contact angle during nucleate pool boiling," International Journal of Heat and Mass Transfer, 50(1-2), 127-138. 


\section{doi:10.1016/j.ijheatmasstransfer.2006.06.037}

Myers, J.G., Yerramilli, V.K., Hussey, S.W., Yee, G.F. and Kim, J., 2005, "Time and Space Resolved Wall Temperature and Heat Flux Measurements during Nucleate Boiling with Constant Heat Flux Boundary Conditions,” Int. J. Heat Mass Transfer, 48, 2429-2442. doi:10.1115/HT-FED2004-56169

Nagayama, G., Tsuruta, T. and Cheng, P., 2006, "Molecular dynamics simulation on bubble formation in a nanochannel," International Journal of Heat and Mass Transfer, 49(23-24), 4437-4443.

doi:10.1016/j.ijheatmasstransfer.2006.04.030

Nielsen, N.J., 1985, "History of the Inkjet Printerhead Development," Hewlett Packard J. 36, 4-10.

Nordmann, D. and Mayinger, F., 1981, "Temperatur, Druck und Warmetransport in der Umgebung kondensierender Blasen,” VDIForschungsheft, 8, 605-618.

Nukiyama, S., 1934, "The Maximum and Minimum Values of Heat Transmitted from Metal to Boiling Water under Atmospheric Pressure,” J. Jpn. Soc. Mech. Eng., 37, 367-374.

doi:10.1016/0017-9310(66)90138-4

Ohnishi, M., Azuma, H., Straub, J., 1999, "Study on Secondary Bubble Creation Induced by Bubble Coalescence,” Gravitational Eff. Mater. Fluid Sci., 24, 1331-1336. doi:10.1016/S0273-1177(99)00742-5

Park, K.A. and Bergles, A.E., 1988, "Effects of Size of Simulated Microelectronic Chips on Boiling and Critical Heat Flux," ASME J. Heat Transfer, 110, 728-734.

doi: $10.1115 / 1.3250552$

Park, S.H., Weng, J.G., and Tien, C.L., 2001, “A molecular dynamics study on surface tension of microbubbles," International Journal of Heat and Mass Transfer, 44(10), 1849-1856.

doi:10.1016/S0017-9310(00)00244-1

Phan, C. M., Nguyen, A.V. and Evans, G.M., 2006, “Combining hydrodynamics and molecular kinetics to predict dewetting between a small bubble and a solid surface," J. Colloidal and Interface Science, 296, 669-676.

doi:10.1016/j.jcis.2005.09.062

Qian, T., Wang, X.P. and Sheng, S., 2006, “A variational approach to moving contact line hydrodynamics,” J. Fluid Mech., 564, 333-360. doi: $10.1017 /$ S0022112006001935

Rainey, K. N. and You, S. M., 2001, "Effects of Heater Size and Orientation on Pool Boiling Heat Transfer From Microporous Coated Surfaces,'” Int. J. Heat Mass Transfer, 44, 2589-2599.

doi:10.1016/S0017-9310(00)00318-5

Rosenhow, M.W., 1952, “A Method of Correlating Heat Transfer Data for Surface Boiling of Liquids," Transactions of the ASME, 4, 969975

Rule, T.D. and Kim, J., 1999, "Heat Transfer Behavior on Small Horizontal Heaters during Pool Boiling in FC-72,” J. Heat Transfer, 121, 386-393.

doi:10.1115/1.2825991

Sadasivan, P., Unal, C., and Nelson, R., 1995, "Perspective: Issues in CHF Modeling - The Need for New Experiments," ASME J. of Heat Transfer, 117, 558-567. doi:10.1115/1.2822614

Sakashita, H. and Kumada, T., 1993, "A New Model for CHF in Pool Boiling at Higher Pressure,” JSME Int. J. Ser. B-fluid Thermal Eng., 36, 422-428.

Sathyamurthi, V., HAhn, .S., Banerjee D., and Lau, S. C., 2009, "Subcooled Pool Boiling Experiments on Horizontal Heaters Coated with Carbon Nanotubes,” Journal of Heat Transfer, 131, 071501. doi: $\underline{10.1115 / 1.3000595}$

Saylor, J.R., Simon, T.W., and Bar-Cohen, A., 1989, "The Effect of a Dimensionless Length Scale on the Critical Heat Flux in Saturated, Pool Boiling,” ASME Publications HTD-108, 71-80.

Schoen, P.A.E., Poulikakos, D. and Arcidiacono, S., 2005, "Phase change of a confined subcooled simple liquid in a nanoscale cavity," Phys. Rev. E, 71(4), 041602.

doi:10.1103/PhysRevE.71.041602

Shikhmurzaev, Y. D., 2006, "Singularities at the moving contact line. Mathematical, physical and computational aspects," Physica D: Nonlinear Phenomena, 217(2), 121-133.

doi: 10.1016/j.physd.2006.03.003

Shin, S., Abdel-Khalik, S.I. and Juric, D., 2005, "Direct threedimensional numerical simulation of nucleate boiling using the level contour reconstruction method," International Journal of Multiphase Flow, 31(10-11), 1231-1242.

doi:10.1016/j.ijmultiphaseflow.2005.06.005

Snyder, N. R. and Edwards, D.K., 1956, "Summary of Conference on Bubble Dynamics And Boiling Heat Transfer," Memo 20-137, Jet Propulsion Laboratory.

Son, G. and Dhir, V.K., 2008, "Numerical simulation of nucleate boiling on a horizontal surface at high heat fluxes," International Journal of Heat and Mass Transfer, 51(9-10), 2566-2582. doi:10.1016/j.ijheatmasstransfer.2007.07.046

Son, G., 2001, "A Numerical Method for Bubble Motion with Phase Change," Numerical Heat Transfer, Part B: Fundamentals: An International Journal of Computation and Methodology, 39(5), 509.

Stephan, P. and Fuchs, T., 2009, "Local heat flow and temperature fluctuations in wall and fluid in nucleate boiling systems," Heat and Mass Transfer, 45(7), 919-928.

doi:10.1007/s00231-007-0320-1

Stephan, P. and Hammer, J., 1994, “A New Model for Nucleate Boiling Heat Transfer,” Warme und Stoffubertragung, 30, 119-12.

doi:10.1007/BF00715018

Stoddard, S.D. and Ford, J., 1973, "Numerical Experiments on the Stochastic Behavior of a Lennard-Jones Gas System," Phys. Rev. A, 8(3), 1504-1512.

doi:10.1103/PhysRevA.8.1504

Sarkar, S., and Selvam, R.P., 2007, "Molecular Dynamics Simulation of Effective Thermal Conductivity and Study of Enhanced Thermal Transport Mechanism in Nanofluids,” J. Appl. Phys., 102, 074302. doi:10.1063/1.2785009

Thompson, P. A., and Robbins, M. O., 1989, "Simulations of contactline motion: Slip and the dynamic contact angle," Phys. Rev. Lett., 63(7), 766-769.

doi:10.1103/PhysRevLett.63.766 
Thompson, P.A., Brinckerhoff, W.B., and Robbins, M.O., 1993, "Microscopic studies of static and dynamic contact angles," Journal of Adhesion Science and Technology, 7(6), 535-554.

doi:10.1163/156856193X00844

Tien, C. L., 1962, “A Hydrodynamic Model for Nucleate Pool Boiling,” International Journal of Heat and Mass Transfer, 5, 540-553. doi:10.1016/0017-9310(62)90164-3

Tomar, G., Biswas, G., Sharma, A. and Agrawal, A., 2005, "Numerical simulation of bubble growth in film boiling using a coupled level-set and volume-of-fluid method," Physics of Fluids, 17(11), 112103. doi:10.1063/1.2136357

Uebbing, J.J., Hengstler, S., Schroeder, D., Venkatesh, S., and Haven, R., 2006, "Heat and Fluid Flow in an Optical Switch Bubble," Journal of Microelectromechanical Systems, 15(6), 1528-1539. doi:10.1109/JMEMS.2006.883529

Wu, J.F. and Dhir, V.K., 2010, "Numerical Simulations of the Dynamics and Heat Transfer Associated With a Single Bubble in Subcooled Pool Boiling," Journal of Heat Transfer-Transactions of the ASME, 132(11).

doi: $\underline{10.1115 / 1.4002093}$

Wu, Y.W., and Pan, C., 2006, "Molecular dynamics simulation of thin film evaporation of Lennard-Jones liquid," Nanoscale and Microscale Thermophysical Engineering, 10, 157.

Yang, Z.L., Dinh, T.N., Nourgaliev, R.R., and Sehgal, B.R., 2000, "Numerical Investigation of Bubble Coalescence Characteristics under
Nucleate Boiling Condition by a Lattice-Boltzmann Model,” Int. J. Thermal Sci., 39, 1-17. doi:10.1016/S1290-0729(00)00199-9

Ye, T., Shyy, W. and Chung, J.N., 2001, "A Fixed-Grid, SharpInterface Method for Bubble Dynamics and Phase Change," Journal of Computational Physics, 174(2), 781-815. doi:10.1006/jcph.2001.6938

You, S.M., Kim, J.H., and K.H. Kim, 2003, "Effect of Nanoparticles on Critical Heat Flux of Water in Pool Boiling Heat Transfer," Applied Physics Letters, 83(16), 3374-3376.

doi:10.1063/1.1619206

Zhang, R., Ikoma, Y., and Motooka, T., 2010, "Negative capillarypressure-induced cavitation probability in nanochannels," Nanotechnology, 21(10), 105706. doi:10.1088/0957-4484/21/10/105706

Zhao, Z., Glod, S., Poulikakos, D., 2000, "Pressure and Power Generation during Explosive Vaporization on a Thin-Film Microheater," Int. J. Heat Mass Transfer, 43, 281-296. doi: $\underline{10.1016 / S 0017-9310(99) 00129-5}$

Zuber, N., 1959, "Hydrodynamic Aspects of Boiling Heat Transfer," AEC Report No. AECU-4439, Physics and Mathematics.

Zuber, N., 1963,“Nucleate Boiling the Region of Isolated Bubbles and the Similarity with Natural Convection,” International Journal of Heat and Mass Transfer, 6, 53-78. doi:10.1016/0017-9310(63)90029-2 